\title{
Nivel de validez y mecanismo procedimental del acto de inscripción en el Registro de Marca de Servicios de la Fiesta Costumbrista del Agua (Tusuy) del distrito de Puquio, Ayacucho, 2016 \\ Validity Level and Procedural Mechanism of the Inscription Act for the Service Trade Mark Registration of the Typical Water Festival (Tusuy) in the District of Puquio, Ayacucho, 2016
}

Felipa Elvira Muñoz Ccuro* Sidney Arangoitia Chalco** http://dx.doi.org/10.21503/lex.v15i19.1375

* Abogada por la Universidad de San Martín de Porres, maestra en Derecho Empresarial y doctora en Derecho por la Universidad Nacional Federico Villarreal. Profesora de pregrado y posgrado de la USMP y UAP. E-mail: f_munoz@uap.edu.pe

** Bachiller en Derecho por la Universidad Alas Peruanas, gerente general de la ONGD Ciudad PEP. Delegado para el Perú de la Cámara Internacional de Comercio Exterior Barcelona - España - CICEX Perú. E-mail: sidicha@yahoo.es

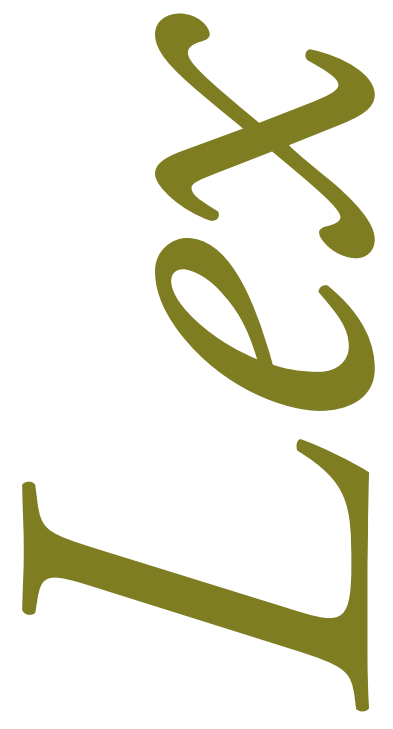




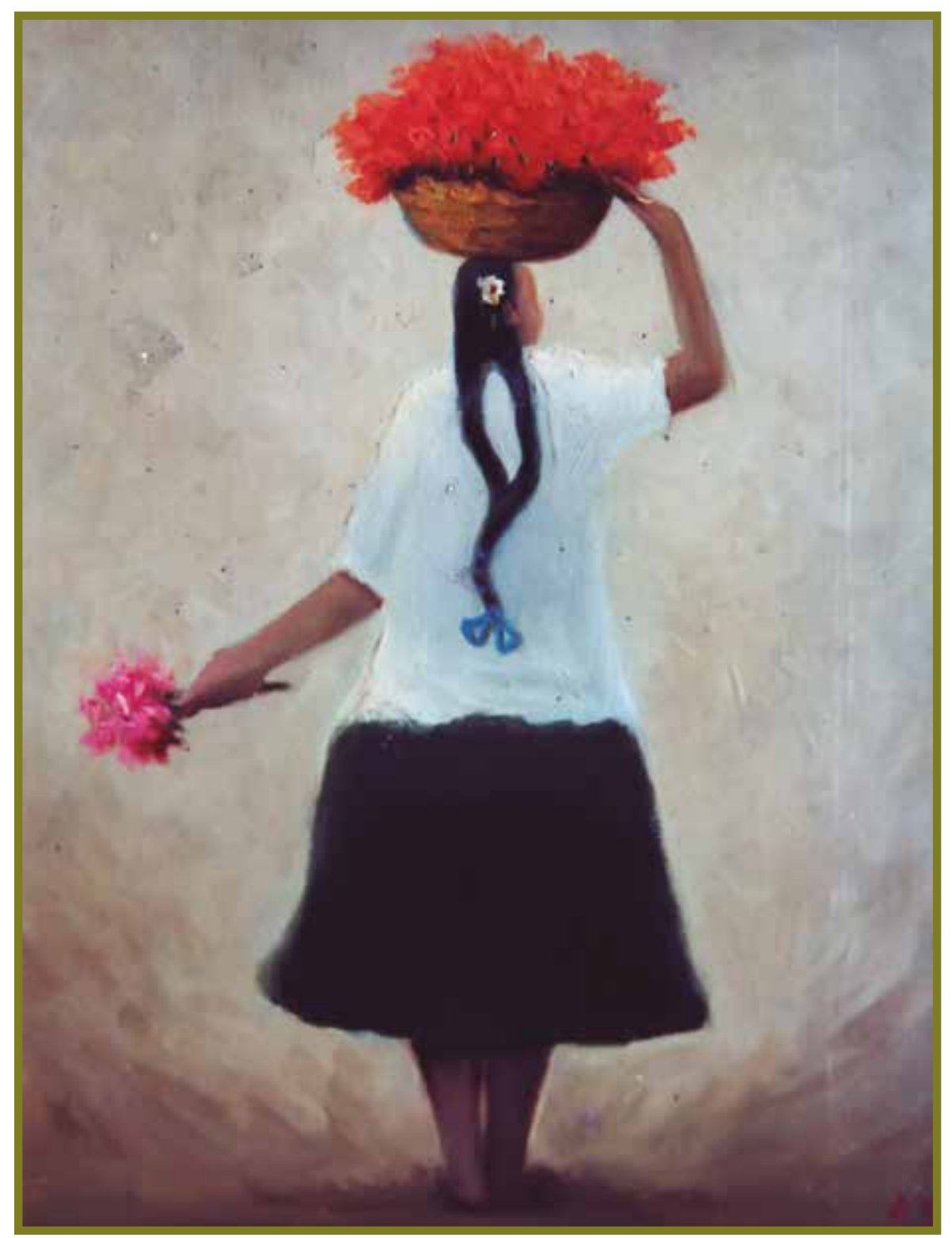

Canasta de flores. Óscar Allaín 


\section{RESUMEN}

El propósito de esta investigación es describir el nivel de validez y mecanismo procedimental del acto de inscripción en el Registro de Marca de Servicios de la Fiesta Costumbrista del Agua (Tusuy) del distrito de Puquio-Ayacucho, 2016. Esta problemática es atendida a través de una propuesta para investigar los mecanismos procedimentales que constituyen la variable 1 y la validez del acto de inscripción de la danza, lo que constituye la variable 2. Los objetivos se centraron en demostrar la situación del patrimonio nacional a través de la presentación de documentos normativos y la aplicación de un cuestionario para medir la opinión de la comunidad con relación al nivel de conocimiento que tenían acerca de la propiedad de las fiestas costumbristas. Para ello se diseñó un instrumento que consiste en un cuestionario con 15 preguntas. Luego se aplicó a 50 sujetos para evidenciar el nivel de conocimiento sobre la legalidad del acto de inscripción; los resultados son analizados a través de estadística descriptiva simple: tabla de frecuencia y figuras. Se concluye que la Fiesta Costumbrista del Agua (Tusuy) es una tradición cultural nativa del distrito de Puquio y los distritos aledaños, con Ley 28296. LEY GENERAL DEL PATRIMONIO CULTURAL DE LA NACIÓN y la RDN N 362/INC2005 (distrito de Andamarca), que la declara Patrimonio Cultural de la Nación. Es una fiesta pública cuya existencia data desde la época precolombina, con extraordinaria significación y simbolismo en el culto al Agua.

Palabras clave: acto de inscripción, registro de marca, fiesta costumbrista, Tusuy.

\section{ABSTRACT}

The purpose of this research is to describe the level of validity and procedural mechanism of the inscription act for the Service Trade Mark Registration of the Typical Water Festival (Tusuy) of the District of Puquio-Ayacucho 2016. This issue is addressed through a proposal to investigate the procedural mechanisms that constitute variable 1 and the validity of the inscription act of the dance, which constitutes the variable 2 . The objectives were focused on supporting the situation of the national heritage by presenting legal documents and the application of a questionnaire to measure the opinion of the community with regards to their knowledge about the ownership of traditional festivals and holidays. An instrument consisting of 15 questions was designed for such purpose. It was then applied to 50 subjects to evidence the level of knowledge about the legality of the registration act; the results are analyzed through simple descriptive statistics: frequency table and figures. It is concluded that the Costa Rican Typical Water Festival (TUSUY) is a cultural native tradition originated in the district of Puquio and surrounding districts, with Law 28296. GENERAL LAW OF THE CULTURAL HERITAGE OF THE 
NATION and RDN N ${ }^{\circ} 362$ / INC-2005 Of Andamarca), which declares it Cultural Heritage of the Nation. It is a Public celebration which existence dates back from pre-Columbian times with extraordinary significance and symbolism in the WATER cult.

Key words: registration act; trade mark registration; typical party; Tusuy. 


\section{INTRODUCCIÓN}

En el planteamiento del problema se presenta un hecho que resulta ser, aparentemente, poco recurrente en los estudios de la dogmática jurídica civil, pero que, ciertamente, ofrece una serie de aristas que merecieron un análisis detallado para su correspondiente debate: la posibilidad de que una manifestación cultural de naturaleza comunal pueda ser objeto de una apropiación por parte de un ente privado mediante un procedimiento administrativo de registro de signos distintivos, lo cual nos llevó a reflexionar sobre la posibilidad, que el derecho de propiedad colectiva de una comunidad campesina o nativa pueda quedar relegado frente al derecho de propiedad privada de una asociación independiente.

Asimismo fue necesario el análisis de un caso concreto a partir del cual se argumenta el presente artículo: Con fecha 3 de abril de 2013, la Asociación Progresista "Hijos de Pichccachuri - Puquio", con sede en Lima, solicitó el registro de la marca de servicio sociocultural "Puquio Sequía Tusuy Fiesta del Agua" y del logotipo en colores ante la Dirección de Signos Distintivos de INDECOPI (Instituto Nacional de Defensa de la Competencia y de la Protección de la Propiedad Intelectual), el cual, luego de verificar el cumplimiento de los requisitos legales respectivos, inscribió la mencionada actividad festiva y el logotipo en el Registro de Marcas de Servicio de Propiedad Industrial para distinguir servicios sociales, culturales y artísticos (organización de fiestas costumbristas, eventos musicales, etcétera), de conformidad con la Clase 41 de la clasificación internacional y con un plazo de diez años de vigencia a partir de la fecha de la emisión de la resolución. En este sentido, la Dirección de Signos Distintivos, mediante la Resolución No 012105-2013/DSD-INDECOPI, emitida con fecha 12 de agosto de 2013, procedió a la inscripción registral antes mencionada y expidió el correspondiente Certificado $N^{\circ} 00077694$.

Ante esta situación, las organizaciones representativas y comunales del distrito de Puquio, provincia de Lucanas, departamento de Ayacucho (autoridades políticas, judiciales, gremiales y comunales), solicitaron a la Dirección de Signos Distintivos de INDECOPI que se declare la nulidad de la Resolución Nº 012105-2013/DSD-INDECOPI y del respectivo Certificado 
No 00077694, por cuanto, atenta contra el legítimo derecho de las comunidades nativas de Puquio para mantener la denominada "Fiesta del Agua" como una costumbre ancestral que está catalogada como patrimonio cultural inmaterial de la humanidad y que no puede ser objeto de apropiación por una organización privada con fines estrictamente lucrativos. Pero INDECOPI nunca dio respuesta alguna.

De lo antes expuesto, nos formulamos la siguiente pregunta: ¡cuál es el nivel de validez y mecanismo procedimental del acto de inscripción en el Registro de Marca de Servicios de INDECOPI de la Fiesta Costumbrista del Agua (Tusuy) del distrito de Puquio, Ayacucho 2016? Para argumentar nuestras conclusiones, presentamos como antecedentes nacionales algunas investigaciones, como el artículo titulado "La propiedad originaria en América: el derecho de propiedad en las comunidades andinas y amazónicas del Perú”. Este precisa que el derecho de propiedad de las comunidades indígenas es totalmente distinto al derecho de propiedad que manejan las personas naturales y jurídicas del ámbito occidental, ya que las comunidades diferencian entre propiedad familiar y propiedad comunal. Asimismo, las comunidades andinas y amazónicas poseen plena autonomía para usar y disponer libremente de sus tierras, así como tienen derechos especiales en el uso de sus recursos naturales bajo los principios de imprescriptibilidad, inalienabilidad e inembargabilidad. ${ }^{1}$ Así también, Herrera ${ }^{2}$ describe en su blog que Julia Illanes denunció que INDECOPI había registrado la denominación Puquio Sequia Tusuy Fiesta del Agua como marca de servicios a favor de la Asociación Progresista Hijos de Pichccachuri, con la Resolución N012105-2013/DSD-INDECOPI; que se organizaron acciones y se presentó memorial de queja ante la oficina responsable para dejar sin efecto dicha resolución; que el registro del nombre FIESTA DEL AGUA excede todo límite, es el summum del atrevimiento y la sinrazón, por decir lo menos. Una manifestación cultural de tanta importancia para nuestros pueblos, la respuesta grupal de agradecimiento a la Madre Naturaleza por la llegada del Agua Nueva que es el principio de la vida y que se conserva con tanta religiosidad por la enfervorizada participación de todos los pueblos, no puede ser manoseada, ofendida de esta manera. Y mucho menos, porque ya el Estado ha proclamado este valor inmanente de la fiesta, al haberla reconocido y registrado COMO PATRIMONIO CULTURAL DE LA NACIÓN, con la Resolución Directoral Nacional N³62/INC, expedida el 22 de marzo del año 2005. La írrita Resolución 012105-2013/DSD-INDECOPI es increíble, en verdad, porque ampara los "servicios de entretenimiento, organización de fiestas, fiestas costumbristas, eventos culturales y sociales musicales de la Clase 41, etcétera”. ¿Alguien podrá entender que Andamarca, o Chilques o San Pedro o Cabana y mil pueblos más DEBAN CONTAR CON LA AUTORIZACIÓN de la fantasmal Asociación Progresista Hijos

1 A. Peña J., "La propiedad originaria en América: el derecho de propiedad en las comunidades andinas y amazónicas del Perú", Ius et Veritas, $\mathrm{N}^{\circ} 45$ (2012).

2 Carlos Herrera, "Mi linda Andamarca", http//andamarca.blogspot.pe/2014/07/mamallay-mama-Registraron-la-fiesta-del-agua_27.html. 
de Pichccachuri para organizar y vivir su Fiesta del Agua como lo acostumbran desde mil años y más?... La rechazada resolución dice "organización de fiestas costumbristas".

También hacemos referencia a investigaciones internacionales, como el trabajo presentado en México por Gómez y Del Villar, ${ }^{3}$ que en su artículo titulado "El concepto de propiedad y los conocimientos tradicionales indígenas" indica que las comunidades indígenas ejercen la propiedad exclusiva sobre sus conocimientos y recursos ancestrales como una manifestación del patrimonio inmaterial de la humanidad y que debe contar con la autorización de estas para realizar cualquier acto de aprovechamiento para el desarrollo científico y tecnológico. Por otro lado, en un artículo en la Revista Caribeña de Ciencias Sociales se plantea que "(...) la interacción cultural va estableciendo transformaciones históricas en las sociedades como proceso de comunicación constante"; no obstante, se resalta que en las comunidades tradicionales también se operan cambios, pero estos, cuando no alteran en lo esencial la identidad, mantienen el sistema de valores, normas y creencias que a pesar de haber evolucionado sustentan su identidad. La sociedad no permanece absolutamente aislada ni ajena a los cambios que acontecen en la actualidad, debido a la interacción entre los individuos y contextos sociales que en algunos casos, llegan incluso a cambiar la identidad de algunas regiones o pueblos. En Bolivia, De La Cruz, R., ${ }^{4}$ en el trabajo denominado "Elementos para la protección sui generis de los conocimientos tradicionales colectivos e integrales desde la perspectiva indígena", señala la necesidad de establecer mecanismos de protección de los conocimientos tradicionales de los pueblos indígenas sobre la base del derecho consuetudinario y las propias prácticas culturales, ya que constituyen parte indisoluble de su cultura y representan un valor estratégico para el desarrollo socioeconómico de estos pueblos y una contribución al desarrollo sostenible de los países andinos. Estos conocimientos tradicionales abarcan una amplia gama de conocimientos, innovaciones y prácticas tradicionales de los pueblos indígenas que tienen relación con la biodiversidad, los aspectos culturales y el folklore. ${ }^{5}$

En la investigación existen, como bases teóricas, algunas teorías como es el caso de las teorías del derecho civil sobre la personería jurídica, o con relación al concepto de persona jurídica, donde se señala que la persona jurídica, aprehendida primariamente a partir de la vida, se presenta como una organización de personas, como una pluralidad de seres huma-

3 M. Gómez y M. del Villar, "El concepto de propiedad y los conocimientos tradicionales indígenas", En-clav. pen 3, N 5, México (jun. 2009) $115-135$.

4 R. de la Cruz, G. Muyuy, A. Viteri, G. Flores, J. González, J. Mirabal y R. Guimaraez. Elementos para la protección sui generis de los conocimientos tradicionales colectivos e integrados desde la perspectiva indígena (Caracas: Corporación Andina de Fomento y Secretaría de la Comunidad Andina, 2005).

5 Carlos Fernández, Naturaleza tridimensional de la persona jurídica. Con especial referencia al derecho peruano, DIKÉ: Portal de Información y Opinión legal, Pontificia Universidad Católica del Perú, http://dike.pucp.edu.pe/bibliotecadeautor_ carlos_fernandez_cesareo/articulos/ba_fs_. 
nos que, a través de una actividad común normativamente regulada, persigue fines valiosos. (...) la persona jurídica está constituida por tres dimensiones que se hallan en recíproca exigencia. Nos referimos a la vida humana social, o sea, la dimensión sociológico-existencial; a los valores que el ser humano vivencia en su vida, es decir, la dimensión axiológica; y, a las normas jurídicas que representan la dimensión formal. Tres diversas vertientes de una misma y única institución jurídica; la teoría sobre las comunidades campesinas y nativas, que la conceptualizan como un tipo especial de personas jurídicas de derecho privado que se regulan por normas de carácter consuetudinario y que se desenvuelven bajo una autonomía funcional, económica y administrativa. Estas comunidades, a pesar de regirse por medio de las normas provenientes de la costumbre y tradición ancestral, se encuentran reguladas por una legislación especial con respecto a su relación con el Estado. ${ }^{6}$ Las comunidades campesinas y nativas se constituyen por el acuerdo de los pobladores de una determinada circunscripción geográfica para formar una organización social que se rija por sus propias reglas de conducta de acuerdo a sus tradiciones y costumbres propias. Las comunidades campesinas y nativas tienen existencia legal por el mero hecho de su existencia en la realidad social, económica y cultural, sin que se necesite de la inscripción registral ni del reconocimiento oficial, que son meros actos declarativos que reconocen una realidad preexistente. El Poder Ejecutivo regula el estatuto de las comunidades campesinas y nativas, el cual consagra su autonomía económica y administrativa así como los derechos y obligaciones de sus miembros y las demás normas para su reconocimiento, inscripción, organización y funcionamiento. La intervención del Poder Ejecutivo en la regulación del estatuto de las comunidades, a través de una norma con rango de decreto supremo por su carácter general, tiene relación con el hecho de que las comunidades campesinas y nativas son personas jurídicas privadas de interés público.

Se hizo necesario revisar fuentes de información sobre la identidad cultural. Así, Molano considera que el concepto de identidad cultural encierra un sentido de pertenencia a un grupo social con el cual se comparten rasgos culturales, como costumbres, valores y creencias. La identidad no es un concepto fijo, sino que se recrea individual y colectivamente y se alimenta continuamente de la influencia exterior. De acuerdo con estudios antropológicos y sociológicos, la identidad surge por oposición y como reafirmación frente al otro. Aunque el concepto de identidad trascienda las fronteras (como en el caso de los migrantes), el origen de este concepto se encuentra frecuentemente vinculado a un territorio. "La identidad cultural de un pueblo viene definida históricamente a través de múltiples aspectos en los que se plasma su cultura, como la lengua, instrumento de comunicación entre los miembros de

6 La Ley No 24656: Ley General de Comunidades Campesinas del 14 de abril de 1987, el Decreto Ley No 22175: Ley de Comunidades Nativas y de Desarrollo Agrario de las Regiones de Selva y Ceja de Selva del 9 de mayo de 1978, y demás normas especiales. 
una comunidad, las relaciones sociales, ritos y ceremonias propias, o los comportamientos colectivos, esto es, los sistemas de valores y creencias. Un rasgo propio de estos elementos de identidad cultural es su carácter inmaterial y anónimo, pues son producto de la colectividad”. Considera que la identidad es el sentido de pertenencia a una colectividad, a un sector social, a un grupo específico de referencia. Esta colectividad puede estar generalmente localizada geográficamente, pero no necesariamente (por ejemplo, los casos de refugiados, desplazados, migrantes, etcétera). Hay manifestaciones culturales que expresan con mayor intensidad que otras su sentido de identidad, hecho que las diferencian de otras actividades que son parte común de la vida cotidiana. Por ejemplo, manifestaciones como la fiesta, el ritual de las procesiones, la música, la danza. A estas representaciones culturales de gran repercusión pública, la UNESCO las ha registrado bajo el concepto de patrimonio cultural inmaterial.

Por otro lado, el contenido de "patrimonio cultural" ha cambiado en las últimas décadas, debido en parte a los instrumentos elaborados por la UNESCO. El patrimonio cultural no se limita a monumentos y colecciones de objetos, sino que comprende también tradiciones o expresiones vivas heredadas de nuestros antepasados y transmitidas a nuestros descendientes, como tradiciones orales, artes del espectáculo, usos sociales, rituales, actos festivos, conocimientos y prácticas relativos a la naturaleza y el universo, y saberes y técnicas vinculados a la artesanía tradicional. La importancia del patrimonio cultural inmaterial no estriba en la manifestación cultural en sí, sino en el acervo de conocimientos y técnicas que se transmiten de generación en generación. El valor social y económico de esta transmisión de conocimientos es pertinente para los grupos sociales tanto minoritarios como mayoritarios de un Estado, y reviste la misma importancia para los países en desarrollo que para los países desarrollados. Como lo define la UNESCO,${ }^{7}$ el patrimonio cultural inmaterial no solo incluye tradiciones heredadas del pasado, sino también usos rurales y urbanos contemporáneos característicos de diversos grupos culturales; no se presta a preguntas sobre la pertenencia de un determinado uso a una cultura, sino que contribuye a la cohesión social fomentando un sentimiento de identidad y responsabilidad que ayuda a los individuos a sentirse miembros de una o varias comunidades y de la sociedad en general; y con relación al patrimonio cultural inmaterial solo puede serlo si es reconocido como tal por las comunidades, grupos o individuos que lo crean, mantienen y transmiten. Sin este reconocimiento, nadie puede decidir por ellos que una expresión o un uso determinado forma parte de su patrimonio.

Ahora bien, con respecto a la Fiesta del Agua, se dice que el Inca Wiracocha por los años 1340 visitaba regularmente la comarca de los rucanas, soras, antamarca y la cultura Nazca; y que después de supervisar las grandes obras que tenía emprendidas en todo el imperio

UNESCO, ¿Qué es el patrimonio cultural inmaterial?, http://www.unesco.org/culture/ich/es/ que-es-el- patrimonio-inmaterial-00003 
incaico, al llegar a la comarca de Puquio, la bautizó con el nombre de Puquio - Puquio ( $p u$ kiupukiu), por existir en la mayor parte de su suelo puquiales de gran magnitud y dividió a esta en cuatro ayllus: Chaupi, Ccollana, Ccayao y Pichccachuri. En su última visita, cuenta la leyenda, que el Inca Wiracocha se enamoró de la hermosa doncella Sasahue, y para ganar sus favores le ofreció darle agua a su pueblo, sobre todo para las tierras eriazas y montescas de Puquio, disponiendo la apertura acelerada de un canal subterráneo que va de Angares a Lucanas, de ciento veinte leguas de longitud que hasta la fecha sigue su curso en una porción regular de agua en el lugar denominado Pedro Saqahue Orqo, lugar sagrado para los ayllus de Puquio, donde en el mes de agosto los aukis y toda su comitiva hacen la pagapa, a más de cuatro mil metros de altura. Asimismo, se considera que la fiesta del agua de Puquio busca la integración e identificación de los hombres del Perú a nivel local y nacional. Para hacerlo, "he querido que nuestros personajes del Tahuantinsuyo, como el auki, el dánsaj, el jarjacha, las waylías, sean los inspiradores de esta integración e identificación totalizadoras, y nuestra visionaria e indómita juventud mestizo-andina, los realizadores del histórico hecho. La integración que propugno es la identificación y connaturalización integral del vecino-misti con el indio-campesino, en todas las formas de la vida espiritual y activa. Idea que ha nacido y está creciendo hoy en todos los pueblos del orbe como una necesidad y respuesta de los pueblos del tercer mundo, en oposición a la cultura occidental que tanto daño de alienación y subrogación nos hicieron durante siglos". ${ }^{8}$

Chiroque transcribe la experiencia de un viajero anónimo, quien relata lo siguiente respecto a la Fiesta del Agua: "Yo había viajado con la profesora María Berrío Casas del Instituto de Pedagogía Popular (IPP), una excelente quechuahablante. ¡Y con ella decidimos quedarnos hasta el sábado 11 de septiembre, día central de la celebración. Ese día nos fuimos a las afueras de Puquio. Miles de campesinos se habían dado cita para recibir el agua. Mi amiga María me traduce lo que una anciana me dice en quechua: "Chay wichay apu orqopin yacuqa tiyan" ("allá, arribita en el cerro vive el agua"). Los auquis se fueron hasta el pico de las montañas y allí hicieron el pago a los apus (dioses) y a la Pachamama (Madre Tierra). El pago consiste en sacrificar una llama y regar la tierra y los puquios con la sangre caliente del animal. Alimentos, chicha y coca complementan el pago.

De repente, la gente se pone de pie y se alborota: ¡aparecen los auquis! ¡Viene el agua! Los llamichus hacen sonar sus huaracas (hondas) y latas de adorno. Gritan. Hablan en quechua. María Berrío me traduce lo que dicen: "Puriy, puriy, yacucha noqaykuwan causay yacucha" ("agüita, agüita, camina, camina, vive con nosotros"). Los campesinos y campesinas beben más. ¡Viene el agua! Para ellos, el agua es motivo de fiesta. Todos beben licor, pero haciendo pago al agua. Me invitan chicha de ayrampo, que es una variedad de tuna, o fruto del nopal

8 R. A. Bendezú N., Puquio y la Fiesta del Agua, tercera edición (Ica, 2010), 116. 
de color rojo intenso que le da ese color y un sabor muy agradable a la bebida. Debo beber chicha de ayrampito, chicha de jora y cañazo. Tengo que hacer también pago a la Pachamanca. Los llamichus se pasean haciendo sus gracias. Momentos centrales. Rocían al agua nueva con llampu, un polvo especial hecho de conchas de mar. Todo el pueblo está alegre. Cantan huainos llenos de sentimiento. Mezcla de alegría, de llanto y de rabia. Beben, bailan y se empujan entre sí ¡Es la fiesta del agua!?

La revista Qawaq refiere que desde la medianoche del sábado hasta el martes, el baile danza de la sekia (Tusuy) se instalará en las calles de los barrios de la ciudad: Pichccachuri, Qayau, y Chaupi. Los cargontes y sus kuyaqs salen a ofrecer generosamente la música contagiante de la alegría a todos y cada uno de los participantes y visitantes. La algarabía es general y el ir y venir del gentío en medio de las vivanderas y vendedores le dan cada vez más un aspecto de feria, y en torno al arpa y violín de cada cargonte pueden danzar los grupos que quieran y estén preparados para ello. Los grupos han de danzar en círculo, bajo la vigilancia del mayordomo, que danzará al centro con un lazo al aire dispuesto a aplicarle castigo a quien no baile adecuadamente. La secuencia tiene sus pasos y saltitos característicos, avances y retrocesos, giros en ambas direcciones que se ejecutan cada intervalo. Pueden ser grupos mixtos de jóvenes, también de adultos y también de ancianos. Terminado el baile-danza de la fiesta de la sekia, los cargontes y mayordomos se preparan y salen al despacho. Este es una ceremonia ritual que tiene sus propios cantos y su propia música inevitablemente triste. Todos los kuyaqs y quienes hayan participado del Yaku Raymi pueden y deben participar. Deben encomendarse al espíritu de nuestro Wamani y a la Pachamama, y despedirnos con respeto hasta el próximo año. ${ }^{10}$

La investigación se proyectó como objetivo describir el nivel de validez y mecanismo procedimental del acto de inscripción en el Registro de Marca de Servicios de INDECOPI de la Fiesta Costumbrista del Agua (Tusuy) del distrito de Puquio, Ayacucho, 2016; y entre otros propósitos identificar el mecanismo procedimental para determinar la validez del acto de inscripción en el Registro de Marca de servicios de la Fiesta Costumbrista del Agua (Tusuy) del distrito de Puquio, Ayacucho, 2016, en favor de una sociedad privada y describir el nivel de validez del acto de inscripción en el Registro de Marca de servicios de la Fiesta Costumbrista del Agua (Tusuy) del distrito de Puquio, Ayacucho 2016, a favor de una sociedad privada. Asimismo, se identificaron como variables de la investigación por un lado el mecanismo procedimental para la inscripción de la Fiesta Costumbrista del Agua (Tusuy) como marca de servicios de propiedad industrial, y por otro la validez del acto de inscripción en el Registro de Marca de Servicios.

9 Ch. Chiroque, Fiesta del Agua, Educación Esperanza, Blog, 23 de diciembre de 2011.

10 Juan Francisco Tincopa, "Pukiu llaqtapi Yaku Raymi o Fiesta del Agua en Puquio", Qawaq, № 13 (1 de enero - 1 de abril de 2011): 19-20, http://revistaqawaq.blogspot.pe/2010/12/angusay-yaku-raymi-enpuquio.html. 


\section{MATERIAL Y MÉTODO}

\subsection{Tipo y nivel de investigación}

a) Tipo de investigación. El estudio corresponde a una investigación exploratoria, pues el estudio tiene como finalidad examinar un tema novedoso o poco estudiado; no experimental, o sea, sin manipulación deliberada de variables; con enfoque cuantitativo y de tipo descriptivo.

b) Nivel de investigación. La investigación corresponde al nivel II de un estudio descriptivo, pues la finalidad es describir el acto de inscripción registral de la fiesta costumbrista Puquio Sequia Tusuy, Fiesta del Agua, como registro de marca de servicios en la División de Propiedad Industrial de INDECOPI y determinar su validez en favor de una sociedad privada o pública.

\subsection{Método y diseño de la investigación}

a) Método de la investigación. Se utilizó el método no experimental descriptivo; es decir, observar el fenómeno tal como se da en su contexto natural, para después analizarlo.

b) Diseño de la investigación. Se debe aclarar que el presente estudio es una investigación no experimental, cuantitativa y descriptiva. Por lo tanto, se ha elegido el diseño transaccional descriptivo que tiene como objetivo indagar la incidencia de las modalidades, categoría o niveles de una o más variables. ${ }^{11}$

El diseño de este trabajo observa y describe el comportamiento de las unidades de análisis para obtener una visión general de los sujetos en estudio, cuyo esquema es el siguiente:

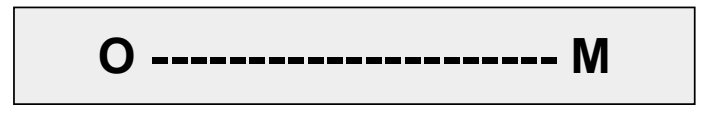

Figura 1

Donde $\mathrm{O}=$ observación y $\mathrm{M}=$ muestra

\subsection{Población y muestra}

a) Población. La población motivo de la investigación está conformada por las autoridades comunales y civiles, así como el grupo de regantes de los cuatro barrios (Ccayao, Pichccachuri, Chaupi y Ccollana) del distrito de Puquio, provincia de Lucanas y departamento de Ayacucho, que forman parte de la comunidad campesina, y se determinó en 1000 unidades de análisis.

11 Roberto. Hernández S., Carlos Fernández C. y Pilar Baptista L., Metodología de la investigación, sexta edición (México: Mc Graw Hill Interamericana, 2006), 155. 
Cuadro $N^{\circ} 1$. Datos de población

\begin{tabular}{|c|c|c|c|}
\hline Ccayao & 250 & Jefe de familia & inscrito \\
\hline Pichccachuri & 230 & Jefe de familia & inscrito \\
\hline Chaupi & 230 & Jefe de familia & inscrito \\
\hline Ccollana & 290 & Jefe de familia & inscrito \\
\hline
\end{tabular}

Fuente: Datos de población según padrón comunal

b) Muestra. La muestra empleada es no probabilística, pues la elección de casos depende del criterio del investigador. Es así que por conveniencia se ha escogido 50 sujetos equivalentes al 5\% del total de la población.

\section{Cuadro $N^{\circ}$ 2. Tamaño de la muestra}

\begin{tabular}{|c|c|c|}
\hline \multicolumn{1}{|c|}{ SUJETOS } & $\mathbf{N}^{\circ}$ & $\%$ \\
\hline Autoridades comunales y civiles & 20 & 40 \\
\hline $\begin{array}{c}\text { Regantes de los barrios de Ccayao, Chaupi, Pichcca- } \\
\text { churi y Ccollana }\end{array}$ & 30 & 60 \\
\hline Total: & $\mathbf{5 0}$ & $\mathbf{1 0 0}$ \\
\hline
\end{tabular}

Fuente: Elaborado por los autores.

\subsection{Técnicas e instrumentos de recolección de datos}

\section{a) Técnicas}

Encuesta. Es un conjunto de preguntas tipificadas dirigidas a una muestra representativa para averiguar estados de opinión o conocer otras cuestiones que les afectan. La encuesta preparada y validada del presente estudio exigió un viaje a Puquio y su aplicación duró tres días.

La estrategia fue identificar por simple nominación a las autoridades civiles y comunales en ejercicio o los que ya fueron y se les aplicó el cuestionario. Los comuneros fueron entrevistados en las calles, en sus chacras o en sus casas, en forma directa y en ocasiones traducida al idioma quechua. No hubo exigencia en obtener respuestas forzadas y se respetaron las emitidas por el informante.

Observación: Se ha observado, la secuencia de la fiesta y en especial el baile-danza denominado Tusuy; segundo, la percepción de las comunidades respecto a la inscripción de su baile en INDECOPI, del cual no tienen referencia alguna. 
Análisis documental: Se ha recogido un ejemplar de la Resolución № 012105-2015 / DSD-INDECOPI, 12 de agosto de 2013, que concede licencia de marca de servicios por 10 años, a partir de 2013 a 2023.

Memorial del 11 de junio 2014, que solicita nulidad de resolución.

Notas de Campo: Se utilizó para anotar las diferentes situaciones observadas y se describió de forma precisa y detallada lo observado en el contexto de ocurrencia, con el fin de aportar información al proceso de investigación.

b) Instrumento

Cuestionario de preguntas. Consta de 15 preguntas estilo Likert, que recoge información sobre los asuntos legales que corresponde a la fiesta costumbrista de la comunidad.

\section{CUESTIONARIO}

El presente cuestionario tiene como propósito medir el nivel conocimiento que usted tiene sobre la Fiesta Costumbrista del Agua (Tusuy) del distrito de Puquio, Ayacucho, con el fin de elaborar una tesis para obtener la licenciatura en Derecho.

Agradecemos su participación.

\begin{tabular}{|c|c|c|c|c|}
\hline \multirow{2}{*}{\multicolumn{2}{|c|}{$\begin{array}{l}\text { Lea atentamente y marque con un aspa }(X) \text { la alternativa que crea conveni- } \\
\text { ente. }\end{array}$}} & \multicolumn{3}{|c|}{ VALORES } \\
\hline & & \multirow{2}{*}{$\frac{\text { MUCHO }}{2}$} & \multirow{2}{*}{$\frac{\text { POCO }}{1}$} & \multirow{2}{*}{$\frac{\text { NADA }}{0}$} \\
\hline $\mathbf{N}^{\circ}$ & Ítems & & & \\
\hline 1 & ¿Conoce Ud. la historia de la fiesta de la sequía de Puquio? & & & \\
\hline 2 & ¿Participa en la fiesta del agua de su comunidad? & & & \\
\hline 3 & ¿Es usted comunero inscrito en su barrio? & & & \\
\hline 4 & ¿Alguna vez ha sido "cargonte" en la fiesta del agua de su comunidad? & & & \\
\hline 5 & $\begin{array}{l}\text { ¿La fiesta del agua permite la identificación de ustedes mismos con la } \\
\text { comunidad? }\end{array}$ & & & \\
\hline 6 & ¿La fiesta del agua permite la diferenciación de grupos? & & & \\
\hline 7 & ¿La fiesta del agua permite la unión de los grupos? & & & \\
\hline 8 & $\begin{array}{l}\text { ¿La fiesta del agua genera recursos económicos en beneficio de la } \\
\text { comunidad? }\end{array}$ & & & \\
\hline 9 & $\begin{array}{l}\text { ¿La fiesta del agua permite exaltar sentimientos espirituales propios } \\
\text { de la comunidad? }\end{array}$ & & & \\
\hline 10 & ¿Conoce las partes o etapas de la fiesta del agua? & & & \\
\hline 11 & $\begin{array}{l}\text { ¿Conoce usted la Resolución de INDECOPI que registra el "Tusuy" de } \\
\text { la fiesta del agua? }\end{array}$ & & & \\
\hline
\end{tabular}




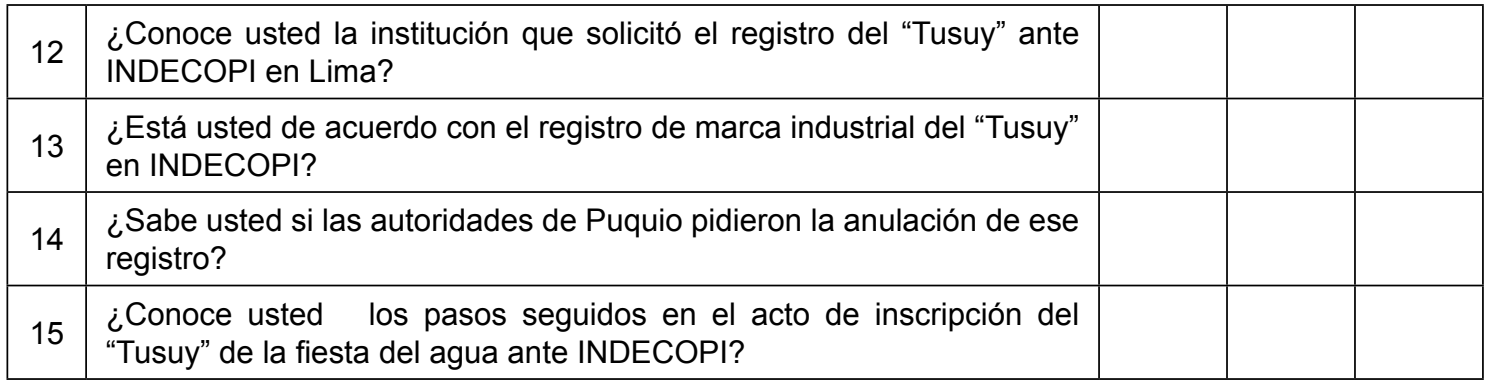

Autor. Sidney Arangoitia Chalco.

Origen. Universidad Alas Peruanas, Facultad de Derecho.

Ámbito de aplicación. Adultos hombres y mujeres de todas las edades.

Tiempo de aplicación. No hay tiempo límite, está en función directa de la comprensión de las instrucciones, disposición de tiempo. Sin embargo, el examen se realiza en un tiempo aproximado de 20 minutos.

Forma de aplicación. Se puede aplicar de manera individual y colectiva.

Significación de la prueba. Da a conocer el nivel de conocimiento que tienen las personas que forman parte de la comunidad acerca de sus derechos y participación en las manifestaciones culturales de su comunidad.

Normas y puntuaciones. La confiabilidad y validez del instrumento se estimó a través del coeficiente del Alfa de Cron Bach.

C) Validación Del Instrumento A Través De Alfa De Cron Bach

\section{Cuadro $\mathbf{N}^{\circ}$ 3. Interpretación de coeficiente de baremos}

\begin{tabular}{|l|l|}
\hline 0,9 & El instrumento de medición es excelente \\
\hline Entre $0,9-0,8$ & El instrumento es bueno \\
\hline Entre $0,8-0,7$ & El instrumento es aceptable \\
\hline Entre $0,7-0,6$ & El instrumento es débil \\
\hline Entre $0,6-0,5$ & El instrumento es pobre \\
\hline Menor 0,5 & No es aceptable \\
\hline
\end{tabular}

Fuente. Elaborado por los autores.

El resultado tiene un valor $\alpha$ de 0,718 , lo que indica que el uso de este instrumento es aceptable para la recolección de datos. 


\section{PRESENTACIÓN, ANÁLISIS E INTERPRETACIÓN DE RESULTADOS}

\subsection{Análisis de tablas y gráficos}

Tabla de frecuencia donde se exponen los resultados del estudio en base a objetivos.

Tabla $\mathrm{N}^{\circ} 1$. Tabla de frecuencias

\begin{tabular}{|c|c|c|c|c|c|c|c|c|c|c|}
\hline \multirow{2}{*}{ Ítems } & \multicolumn{2}{|c|}{$\begin{array}{c}\text { Mucho } \\
(\mathbf{2})\end{array}$} & \multicolumn{2}{c|}{$\begin{array}{c}\text { Poco } \\
(\mathbf{1})\end{array}$} & \multicolumn{2}{c|}{$\begin{array}{c}\text { Nada } \\
(\mathbf{0})\end{array}$} & \multicolumn{2}{c|}{ Anulado } & \multicolumn{2}{c|}{ Total } \\
\cline { 2 - 12 } & $\mathbf{N}^{\circ}$ & $\%$ & $\mathbf{N}^{\circ}$ & $\%$ & $\mathbf{N}^{\circ}$ & $\%$ & $\mathbf{N}^{\circ}$ & $\%$ & $\mathbf{N}^{\circ}$ & $\%$ \\
\hline 1 & 23 & 46 & 25 & 50 & 2 & 4 & - & - & 50 & 100 \\
\hline 2 & 28 & 56 & 19 & 38 & 3 & 6 & - & - & 50 & 100 \\
\hline 3 & 18 & 36 & 5 & 10 & 27 & 54 & - & - & 50 & 100 \\
\hline 4 & 22 & 44 & 2 & 4 & 26 & 52 & - & - & 50 & 100 \\
\hline 5 & 34 & 68 & 10 & 20 & 5 & 10 & 1 & 2 & 50 & 100 \\
\hline 6 & 15 & 30 & 14 & 28 & 20 & 40 & 1 & 2 & 50 & 100 \\
\hline 7 & 30 & 60 & 8 & 16 & 12 & 24 & - & - & 50 & 100 \\
\hline 8 & 15 & 30 & 11 & 22 & 24 & 48 & - & - & 50 & 100 \\
\hline 9 & 41 & 82 & 7 & 14 & 2 & 4 & - & - & 50 & 100 \\
\hline 10 & 33 & 66 & 14 & 28 & 3 & 6 & - & - & 50 & 100 \\
\hline 11 & 7 & 14 & 8 & 16 & 35 & 70 & - & - & 50 & 100 \\
\hline 12 & 5 & 10 & 6 & 12 & 38 & 76 & 1 & 2 & 50 & 100 \\
\hline 13 & 5 & 10 & 6 & 12 & 39 & 78 & & - & 50 & 100 \\
\hline 14 & 4 & 8 & 7 & 14 & 38 & 76 & 1 & 2 & 50 & 100 \\
\hline 15 & 2 & 4 & 3 & 6 & 45 & 90 & - & - & 50 & 100 \\
\hline
\end{tabular}

Fuente: elaborado con los datos del cuestionario.

\section{Análisis cualitativo}

En el ítem $\mathrm{N}^{\circ} 1$, el $50 \%$ (25) de los sujetos de la muestra conoce poco la historia de la fiesta de la sequía de Puquio, un 46 \% (23) conoce mucho de esta fiesta, mientras que solo el $4 \%$ (2) no conoce esta celebración. Esto indica que la gente sí tiene conocimiento de la fiesta de su comunidad.

En el ítem $\mathrm{N}^{\circ} 2$, el $56 \%$ (28) de los encuestados participa en la fiesta del agua de su comunidad, el $38 \%$ (19) participa poco y un 6\% (3) no participa. Los datos indican que un número significativo de los miembros de la comunidad participa en la fiesta del agua.

En el ítem $\mathrm{N}^{\circ} 3$, el $54 \%$ (27) corresponde a los miembros de la comunidad que no están inscritos en su barrio, otro $36 \%$ (18) se encuentra inscrito en su barrio, mientras que el 10 
\% (5) se muestra indiferente. Los datos muestran que la gente participa en la fiesta del agua; sin embargo, no tienen interés por afiliarse.

En el ítem $\mathrm{N}^{\circ} 4$, el $52 \%$ (26) de los sujetos nunca han sido cargontes en la fiesta del agua de su comunidad, el $44 \%$ (22) sí han sido cargontes varias veces, y solo el 4 \% (2) nunca fueron cargontes. Los resultados muestran el fervor social de la comunidad y su identidad para participar en las fiestas de su comunidad.

En el ítem No 5, el $68 \%$ (34) de los encuestados refiere que la fiesta del agua permite la identificación de ellos con la comunidad; un $20 \%$ (10) refiere que poco, mientras que el $10 \%$ (5) no cree.

En el ítem $\mathrm{N}^{\circ}$ 6, el $40 \%$ (20) de los sujetos encuestados opina que la fiesta del agua no permite la diferenciación de grupos; el 28 \% (14) afirma que permite poco la diferenciación de los grupos. Si pensamos que la fiesta de la comunidad es integración, encontramos que en el grupo de encuestados el 30 \% (15) opina que la fiesta del agua permite mucho la diferenciación de los grupos.

En el ítem $\mathrm{N}^{\circ} 7$, el $60 \%$ (30) refiere que la fiesta del agua permite mucho la unión de los grupos, el $24 \%$ (12) afirma que no permite la unión de los grupos, mientras que el $16 \%$ (8) opina que permite poco la unión de los grupos. En conclusión, los comuneros piensan que esta fiesta no permite la unión de los grupos.

En el ítem $N^{\circ} 8$, el $48 \%$ (24) de los sujetos encuestados afirma que la fiesta del agua no genera recursos económicos en beneficio de la comunidad; otro $22 \%$ (11) refiere que genera pocos recursos económicos en beneficio de la comunidad, mientras que el $30 \%$ (15) de sujetos afirma que genera mucho beneficio económico a la comunidad. Al parecer, la gente desconoce los beneficios económicos que aportan las fiestas costumbristas a la comunidad.

En el ítem $\mathrm{N}^{\circ}$ 9, un $82 \%$ (41) de las unidades de análisis afirma que la fiesta del agua permite exaltar sentimientos espirituales propios de la comunidad, un $14 \%$ (7) refiere que influye poco, y solo un $4 \%$ (2) opina que no permite la exaltación de los sentimientos espirituales. En su mayoría, las personas encuestadas afirman que la fiesta del agua permite la exaltación de sentimientos espirituales en la comunidad.

En el ítem $\mathrm{N}^{\circ} 10$, el $66 \%$ (33) de los encuestados conoce mucho las partes o etapas de la fiesta del agua, el $28 \%$ (14) conoce poco, y el $6 \%$ (3) no conoce nada sobre las etapas de la fiesta del agua.

En el ítem $N^{\circ} 11$, el $70 \%$ (35) no conoce nada de la Resolución de INDECOPI que registra la fiesta del agua, el $16 \%$ (8) conoce poco, el $14 \%$ (7) conoce mucho. En conclusión, los sujetos encuestados desconocen los aspectos normativos de la fiesta del agua. 
En el ítem $\mathrm{N}^{\circ} 12$, el $76 \%$ (38) de sujetos encuestados no conoce la institución que solicitó el registro del "Tusuy" ante INDECOPI en Lima; un $12 \%$ (6) conoce poco, mientras que el $10 \%$ (5) sí conoce mucho. Por los resultados podemos deducir que la mayoría de comuneros desconoce los trámites legales para registrar un bien de la comunidad.

En el ítem $\mathrm{N}^{\circ} 13$, el $78 \%$ (39) de unidades de análisis refiere que no está de acuerdo con el registro de marca industrial del "Tusuy" en INDECOPI, el $12 \%$ (6) está poco de acuerdo, mientras que el $10 \%(5)$ está muy de acuerdo.

En el ítem $\mathrm{N}^{\circ} 14$, el $76 \%$ (38) no sabe nada si las autoridades de Puquio pidieron la anulación del registro de la fiesta del agua, el $14 \%$ (7) sabe poco, y solo el $8 \%$ (4) sabe mucho. $\mathrm{Al}$ parecer, la comunidad desconoce sobre los asuntos legales de la fiesta de su comunidad.

En el ítem $N^{\circ} 15$, el $90 \%$ (45) no conoce nada sobre los pasos seguidos en el acto de inscripción del "Tusuy" de la fiesta del agua ante INDECOPI, solo un 4 \% (2) conoce mucho sobre esta actividad. Esto indica que los miembros de la comunidad desconocen los asuntos legales de las fiestas patronales de su comunidad, en este caso, de la Fiesta del Agua de Puquio, en Ayacucho.

\subsection{Resultados en base a objetivos}

\section{$>$ Objetivo específico $\mathrm{N}^{\circ} 1$}

Identificar el mecanismo procedimental para determinar la validez del acto de inscripción en el Registro de Marca de Servicios de la Fiesta Costumbrista del Agua (Tusuy) del distrito de Puquio, Ayacucho, 2016, en favor de una sociedad privada.

Dan fe de este objetivo los ítems 11, 13 y 15.

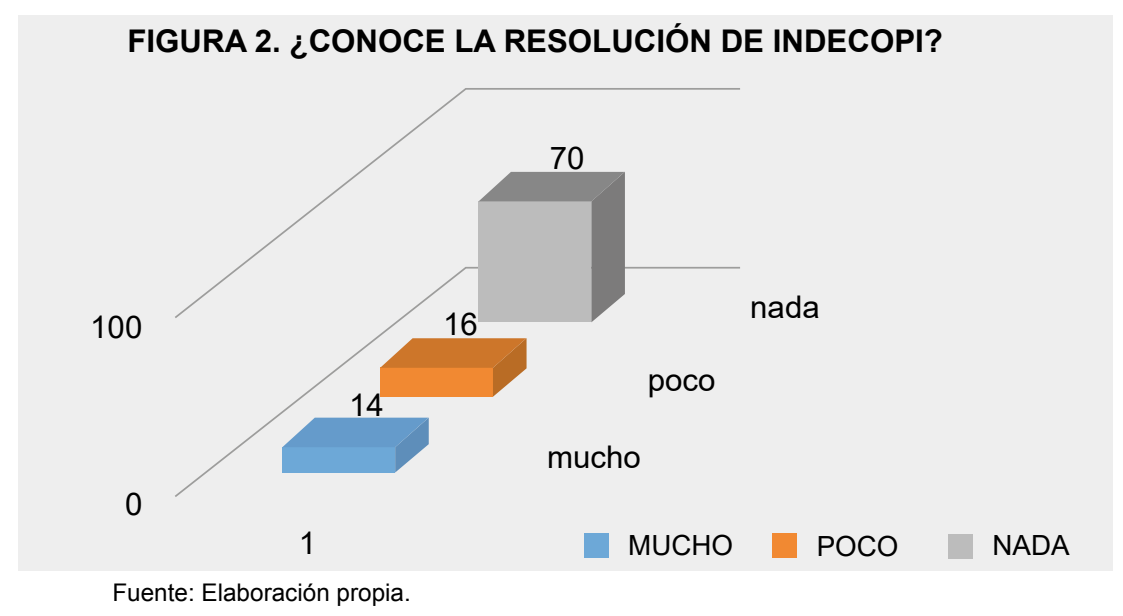


Tabla N². ¿Conoce usted la Resolución de INDECOPI que registra el "Tusuy" de la fiesta del agua?

\begin{tabular}{|c|c|c|c|c|c|c|c|c|c|c|}
\hline \multirow{2}{*}{ items } & \multicolumn{2}{|c|}{$\begin{array}{c}\text { Mucho } \\
\text { (2) }\end{array}$} & \multicolumn{2}{c|}{$\begin{array}{c}\text { Poco } \\
\text { (1) }\end{array}$} & \multicolumn{2}{c|}{$\begin{array}{c}\text { Nada } \\
\text { (0) }\end{array}$} & \multicolumn{2}{c|}{ anulado } & \multicolumn{2}{c|}{ total } \\
\cline { 2 - 12 } & $\mathbf{N}^{\circ}$ & $\%$ & $\mathbf{N}^{\circ}$ & $\%$ & $\mathbf{N}^{\circ}$ & $\%$ & $\mathbf{N}^{\circ}$ & $\%$ & $\mathbf{N}^{\circ}$ & $\%$ \\
\hline 11 & 7 & 14 & 8 & 16 & 35 & 70 & - & - & 50 & 100 \\
\hline
\end{tabular}

\section{Análisis cualitativo}

El $70 \%$ (35) no conoce la Resolución de INDECOPI que registra la fiesta del agua, el $16 \%$ (8) conoce poco, el $14 \%$ (7) conoce mucho. En conclusión, los sujetos encuestados desconocen los aspectos normativos de la fiesta del agua.

\section{FIGURA 3. ¿CONOCE LA INSTITUCIÓN QUE SOLICITÓ REGISTRO ANTE INDECOPI?}

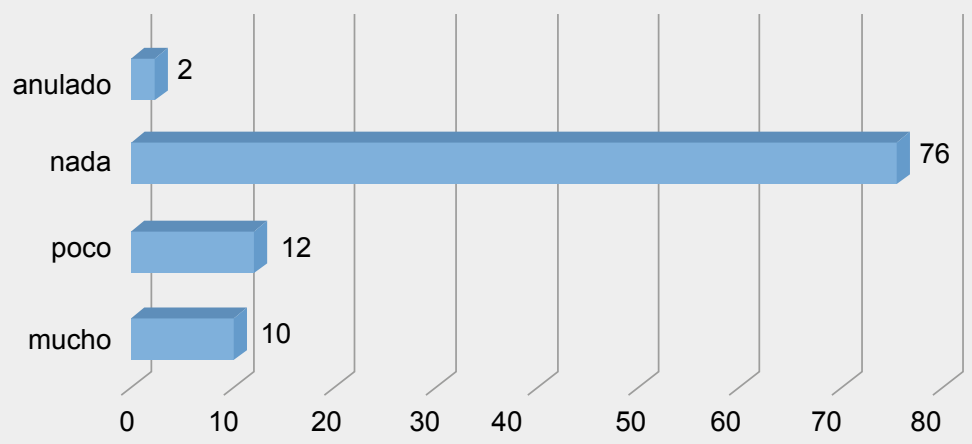

Tabla $\mathbf{N}^{\circ}$ 3. ¿Conoce usted la institución que solicitó el registro del "Tusuy" ante INDECOPI en Lima?

\begin{tabular}{|c|c|c|c|c|c|c|c|c|c|c|}
\hline \multirow{2}{*}{ Ítems } & \multicolumn{2}{|c|}{$\begin{array}{c}\text { Mucho } \\
\text { (2) }\end{array}$} & \multicolumn{2}{c|}{$\begin{array}{c}\text { Poco } \\
\text { (1) }\end{array}$} & \multicolumn{2}{c|}{$\begin{array}{c}\text { Nada } \\
\text { (0) }\end{array}$} & \multicolumn{2}{c|}{ Anulado } & \multicolumn{2}{c|}{ Total } \\
\cline { 2 - 11 } & $\mathbf{N}^{\circ}$ & $\%$ & $\mathbf{N}^{\circ}$ & $\%$ & $\mathbf{N}^{\circ}$ & $\%$ & $\mathbf{N}^{\circ}$ & $\%$ & $\mathbf{N}^{\circ}$ & $\%$ \\
\hline 12 & 5 & 10 & 6 & 12 & 38 & 76 & 1 & 2 & 50 & 100 \\
\hline
\end{tabular}

\section{Análisis cualitativo}

El $76 \%$ (38) de sujetos encuestados no conoce la institución que solicitó el registro del "Tusuy" ante INDECOPI, en Lima; un 12 \% (6) conoce poco, mientras que el 10 \% (5) sí conoce mucho. Por los resultados podemos deducir que la mayoría de comuneros desconoce los trámites legales para registrar un bien de la comunidad. 


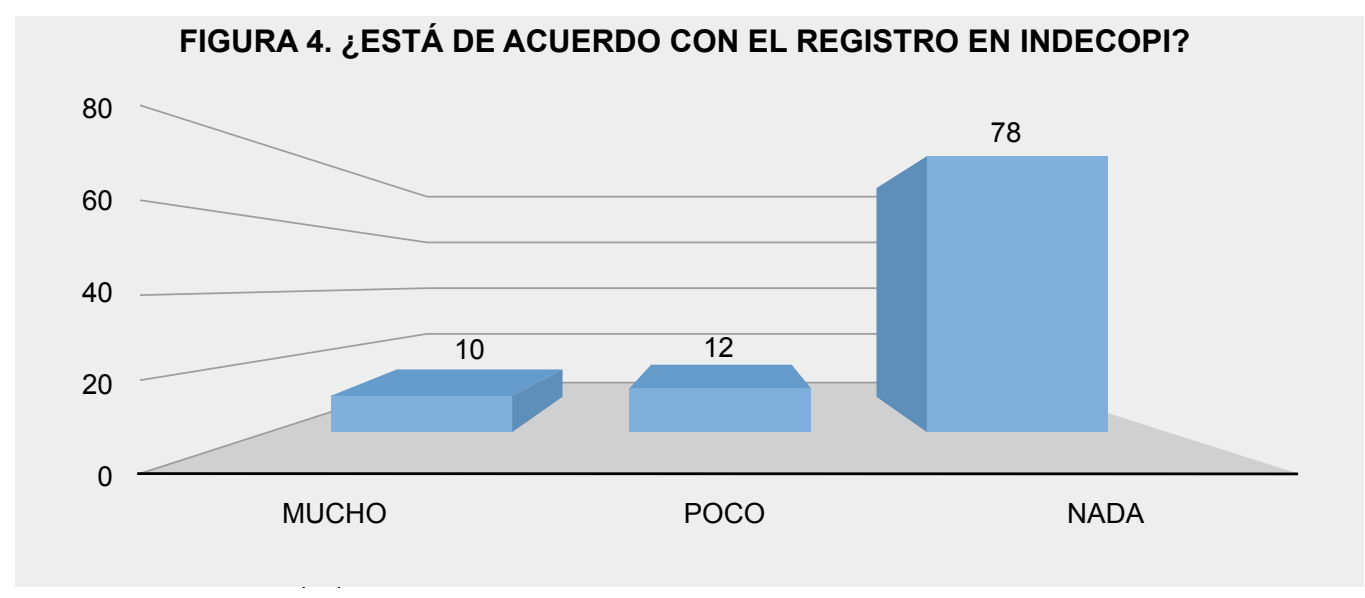

Tabla $N^{\circ} 4$. ¿Está usted de acuerdo con el registro de marca industrial del "Tusuy" en INDECOPI?

\begin{tabular}{|c|c|c|c|c|c|c|c|c|c|c|}
\hline \multirow{2}{*}{ Ítems } & \multicolumn{2}{|c|}{$\begin{array}{c}\text { Mucho } \\
\text { (2) }\end{array}$} & \multicolumn{2}{c|}{$\begin{array}{c}\text { Poco } \\
\text { (1) }\end{array}$} & \multicolumn{2}{c|}{$\begin{array}{c}\text { Nada } \\
\text { (0) }\end{array}$} & \multicolumn{2}{c|}{ Anulado } & \multicolumn{2}{c|}{ Total } \\
\cline { 2 - 11 } & $\mathbf{N}^{\circ}$ & $\%$ & $\mathbf{N}^{\circ}$ & $\%$ & $\mathbf{N}^{\circ}$ & $\%$ & $\mathbf{N}^{\circ}$ & $\%$ & $\mathbf{N}^{\circ}$ & $\%$ \\
\hline 13 & 5 & 10 & 6 & 12 & 39 & 78 & - & - & 50 & 100 \\
\hline
\end{tabular}

\section{Análisis cualitativo}

El $78 \%$ (39) unidades de análisis refiere que no está de acuerdo con el registro de marca industrial del “Tusuy” en INDECOPI, el $12 \%$ (6) está poco de acuerdo, mientras que el 10 $\%$ (5) está muy de acuerdo.

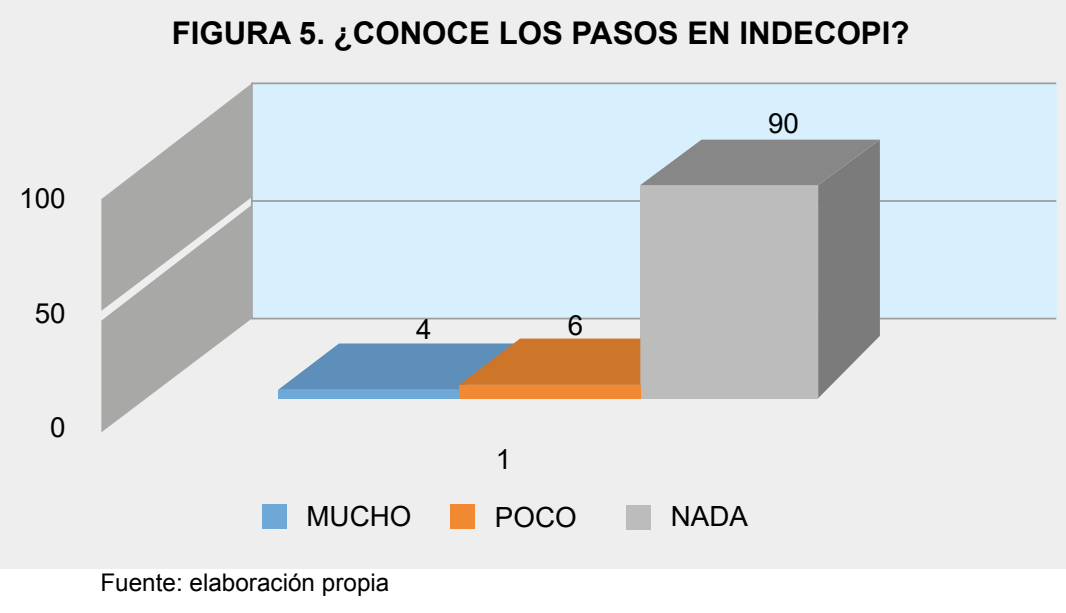


Tabla $N^{\circ}$ 5. ¿Conoce usted los pasos seguidos en el acto de inscripción de la fiesta del agua ante INDECOPI?

\begin{tabular}{|c|c|c|c|c|c|c|c|c|c|c|}
\hline \multirow{2}{*}{ ítems } & \multicolumn{2}{|c|}{$\begin{array}{c}\text { Mucho } \\
\text { (2) }\end{array}$} & \multicolumn{2}{c|}{$\begin{array}{c}\text { Poco } \\
\text { (1) }\end{array}$} & \multicolumn{2}{c|}{$\begin{array}{c}\text { Nada } \\
\text { (0) }\end{array}$} & \multicolumn{2}{c|}{ Anulado } & \multicolumn{2}{c|}{ Total } \\
\cline { 2 - 11 } & $\mathbf{N}^{\circ}$ & $\%$ & $\mathbf{N}^{\circ}$ & $\%$ & $\mathbf{N}^{\circ}$ & $\%$ & $\mathbf{N}^{\circ}$ & $\%$ & $\mathbf{N}^{\circ}$ & $\%$ \\
\hline 15 & 2 & 4 & 3 & 6 & 45 & 90 & - & - & 50 & 100 \\
\hline
\end{tabular}

\section{Análisis cualitativo}

El 90 \% (45) no conoce los pasos seguidos en el acto de inscripción del "Tusuy" de la fiesta del agua ante INDECOPI, solo un $4 \%$ (2) conoce mucho sobre esta actividad. Esto indica que los miembros de la comunidad desconocen los asuntos legales de las fiestas patronales de su comunidad, en este caso de la Fiesta del Agua de Puquio, Ayacucho.

\section{Objetivo específico $\mathrm{N}^{\circ} 2$}

Describir el nivel de validez del acto de inscripción en el Registro de Marca de Servicios de la Fiesta Costumbrista del Agua (Tusuy) del distrito de Puquio, Ayacucho 2016, a favor de una sociedad privada.

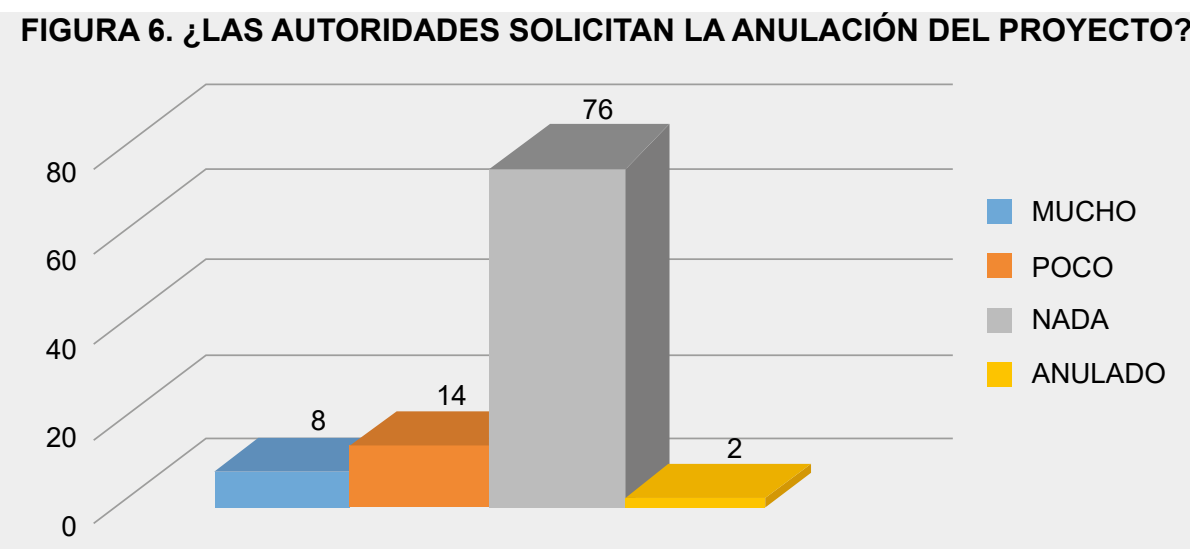

- Validez legal

Tabla $N^{\circ}$ 6. ¿Sabe usted si las autoridades de Puquio pidieron la anulación de ese registro?

\begin{tabular}{|c|c|c|c|c|c|c|c|c|c|c|}
\hline \multirow{2}{*}{ Ítems } & \multicolumn{2}{|c|}{$\begin{array}{c}\text { Mucho } \\
\text { ( 2) }\end{array}$} & \multicolumn{2}{c|}{$\begin{array}{c}\text { Poco } \\
\text { (1) }\end{array}$} & \multicolumn{2}{c|}{$\begin{array}{c}\text { Nada } \\
\text { ( 0) }\end{array}$} & \multicolumn{2}{c|}{ Anulado } & \multicolumn{2}{c|}{ Total } \\
\cline { 2 - 12 } & $\mathbf{N}^{\circ}$ & $\%$ & $\mathbf{N}^{\circ}$ & $\%$ & $\mathbf{N}^{\circ}$ & $\%$ & $\mathbf{N}^{\circ}$ & $\%$ & $\mathbf{N}^{\circ}$ & $\%$ \\
\hline 14 & 4 & 8 & 7 & 14 & 38 & 76 & 1 & 2 & 50 & 100 \\
\hline
\end{tabular}




\section{Análisis cualitativo}

El 76 \% (38) no sabe si las autoridades de Puquio pidieron la anulación del registro de la fiesta del agua, el $14 \%$ (7) sabe poco, y solo el 8\% (4) sabe mucho. Al parecer, la comunidad desconoce sobre los asuntos legales de la fiesta de su comunidad.

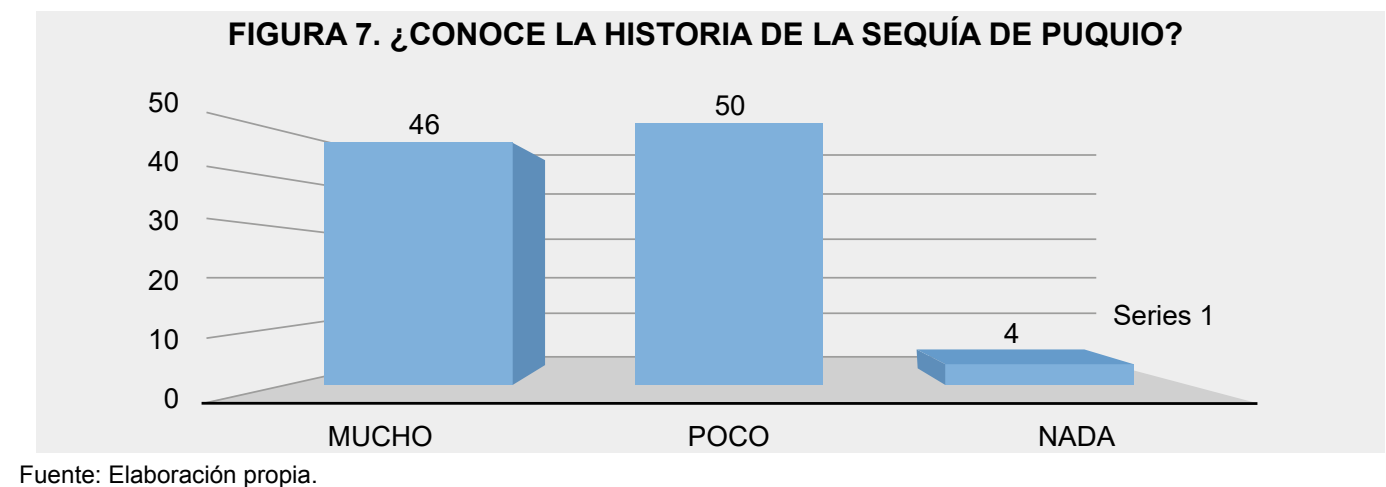

- Validez social

Tabla $N^{\circ} 7$. ¿Conoce Ud. la historia de la fiesta de la Sequía de Puquio?

\begin{tabular}{|c|c|c|c|c|c|c|c|c|c|c|}
\hline \multirow{2}{*}{ ítems } & \multicolumn{2}{|c|}{$\begin{array}{c}\text { Mucho } \\
\text { (2) }\end{array}$} & \multicolumn{2}{c|}{$\begin{array}{c}\text { Poco } \\
\text { (1) }\end{array}$} & \multicolumn{2}{c|}{$\begin{array}{c}\text { Nada } \\
\text { (0) }\end{array}$} & \multicolumn{2}{c|}{ Anulado } & \multicolumn{2}{|c|}{ Total } \\
\cline { 2 - 11 } & $\mathbf{N}^{\circ}$ & $\%$ & $\mathbf{N}^{\circ}$ & $\%$ & $\mathbf{N}^{\circ}$ & $\%$ & $\mathbf{N}^{\circ}$ & $\%$ & $\mathbf{N}^{\circ}$ & $\%$ \\
\hline 1 & 23 & 46 & 25 & 50 & 2 & 4 & - & - & 50 & 100 \\
\hline
\end{tabular}

\section{Análisis cualitativo}

El $50 \%$ (25) de los sujetos de la muestra conocen poco la historia de la fiesta de la sequía de Puquio, un $46 \%$ (23) conoce mucho de esta fiesta, mientras que solo el 4 \% (2) no conoce esta celebración. Esto indica que la gente sí tiene conocimiento de la fiesta de su comunidad.

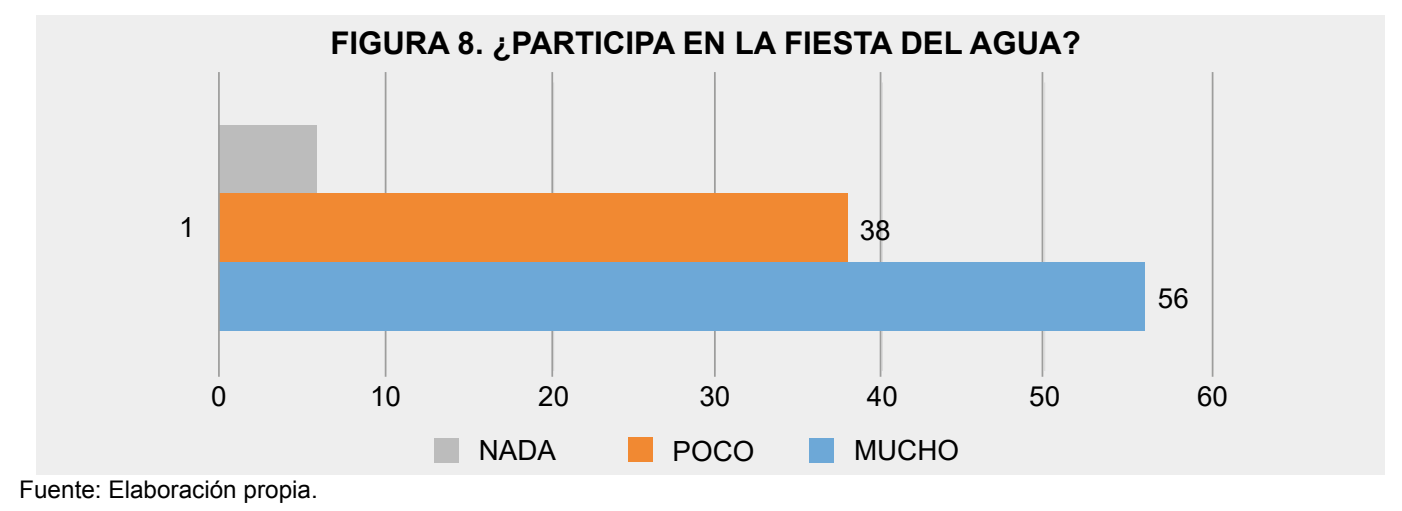


Tabla $N^{\circ}$ 8: ¿Participa en la fiesta del agua de su comunidad?

\begin{tabular}{|c|c|c|c|c|c|c|c|c|c|c|}
\hline \multirow{2}{*}{ Ítems } & \multicolumn{2}{|c|}{$\begin{array}{c}\text { Mucho } \\
\text { (2) }\end{array}$} & \multicolumn{2}{c|}{$\begin{array}{c}\text { Poco } \\
\text { (1) }\end{array}$} & \multicolumn{2}{c|}{$\begin{array}{c}\text { Nada } \\
\text { (0) }\end{array}$} & \multicolumn{2}{c|}{ Anulado } & \multicolumn{2}{c|}{ Total } \\
\cline { 2 - 11 } & $\mathbf{N}^{\circ}$ & $\%$ & $\mathbf{N}^{\circ}$ & $\%$ & $\mathbf{N}^{\circ}$ & $\%$ & $\mathbf{N}^{\circ}$ & $\%$ & $\mathbf{N}^{\circ}$ & $\%$ \\
\hline 2 & 28 & 56 & 19 & 38 & 3 & 6 & - & - & 50 & 100 \\
\hline
\end{tabular}

\section{Análisis cualitativo}

El $56 \%$ (28) de los encuestados participa en la fiesta del agua de su comunidad; el $38 \%$ (19) participa poco y un $6 \%$ (3) no participa. Los datos indican que un número significativo de los miembros de la comunidad participa en la fiesta del agua.

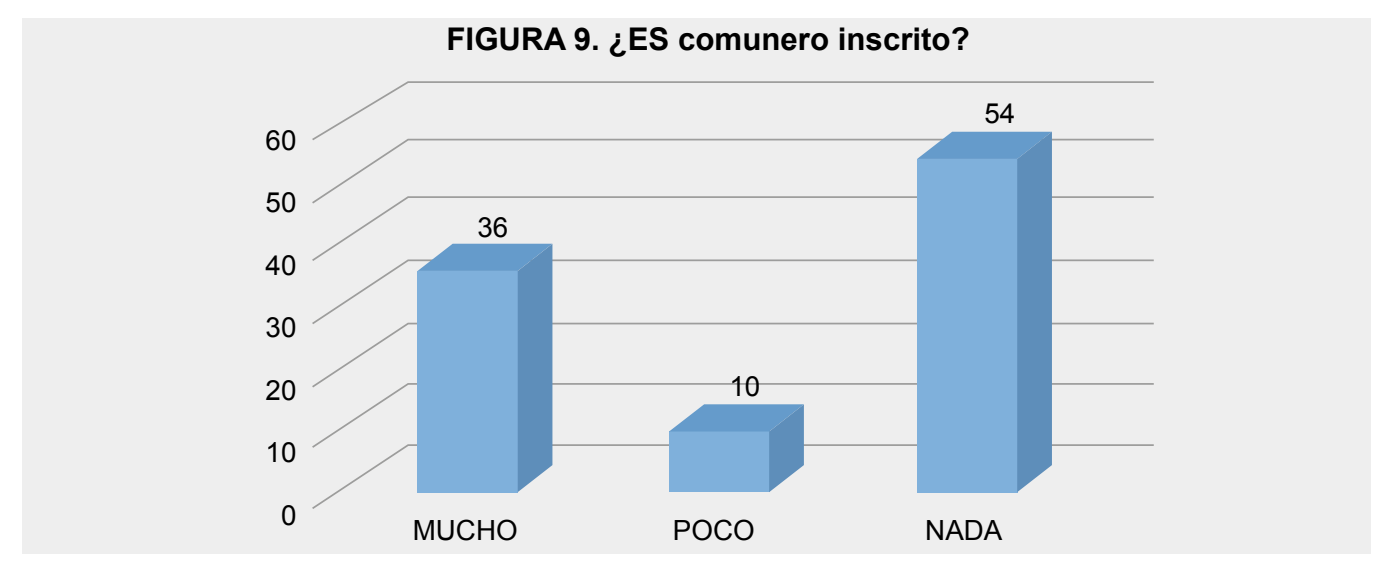

Fuente: Elaboración propia.

Tabla $N^{\circ}$ 9. ¿Es usted comunero inscrito en su barrio?

\begin{tabular}{|c|c|c|c|c|c|c|c|c|c|c|}
\hline \multirow{2}{*}{ Ítems } & \multicolumn{2}{|c|}{$\begin{array}{c}\text { Mucho } \\
\text { (2) }\end{array}$} & \multicolumn{2}{c|}{$\begin{array}{c}\text { Poco } \\
\text { (1) }\end{array}$} & \multicolumn{2}{c|}{$\begin{array}{c}\text { Nada } \\
\text { (0) }\end{array}$} & \multicolumn{2}{c|}{ Anulado } & \multicolumn{2}{c|}{ Total } \\
\cline { 2 - 12 } & $\mathbf{N}^{\circ}$ & $\%$ & $\mathbf{N}^{\circ}$ & $\%$ & $\mathbf{N}^{\circ}$ & $\%$ & $\mathbf{N}^{\circ}$ & $\%$ & $\mathbf{N}^{\circ}$ & $\%$ \\
\hline 3 & 18 & 36 & 5 & 10 & 27 & 54 & - & - & 50 & 100 \\
\hline
\end{tabular}

\section{Análisis cualitativo}

El $54 \%$ (27) de los miembros de la comunidad no está inscrito en su barrio, otro $36 \%$ (18) se encuentra inscrito en su barrio, mientras que el $10 \%$ (5) se muestra indiferente. Los datos muestran que la gente participa en la fiesta del agua; sin embargo, no tienen interés por afiliarse. 


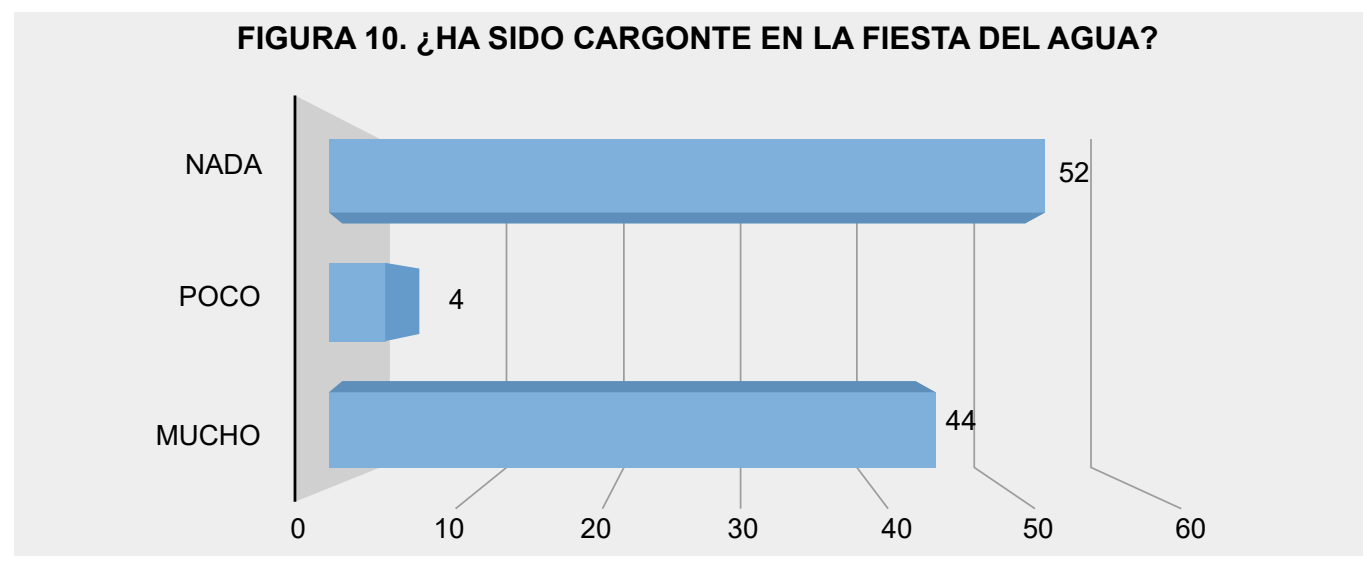

Fuente: Elaboración propia.

Tabla $N^{\circ} 10$. ¿Alguna vez ha sido "cargonte" en la fiesta del agua de su comunidad?

\begin{tabular}{|c|c|c|c|c|c|c|c|c|c|c|}
\hline \multirow{2}{*}{ Ítems } & \multicolumn{2}{|c|}{$\begin{array}{c}\text { Mucho } \\
\text { (2) }\end{array}$} & \multicolumn{2}{c|}{$\begin{array}{c}\text { Poco } \\
\text { (1) }\end{array}$} & \multicolumn{2}{c|}{$\begin{array}{c}\text { Nada } \\
\text { (0) }\end{array}$} & \multicolumn{2}{c|}{ Anulado } & \multicolumn{2}{c|}{ Total } \\
\cline { 2 - 11 } & $\mathbf{N}^{\circ}$ & $\%$ & $\mathbf{N}^{\circ}$ & $\%$ & $\mathbf{N}^{\circ}$ & $\%$ & $\mathbf{N}^{\circ}$ & $\%$ & $\mathbf{N}^{\circ}$ & $\%$ \\
\hline 4 & 22 & 44 & 2 & 4 & 26 & 52 & - & - & 50 & 100 \\
\hline
\end{tabular}

\section{Análisis cualitativo}

El $52 \%$ (26) de los sujetos nunca han sido cargontes en la fiesta del agua de su comunidad, el $44 \%$ (22) sí han sido cargontes varias veces, y solo el 4 \% (2) nunca fueron cargontes. Los resultados muestran el fervor social de la comunidad y su identidad para participar en las fiestas de su comunidad.

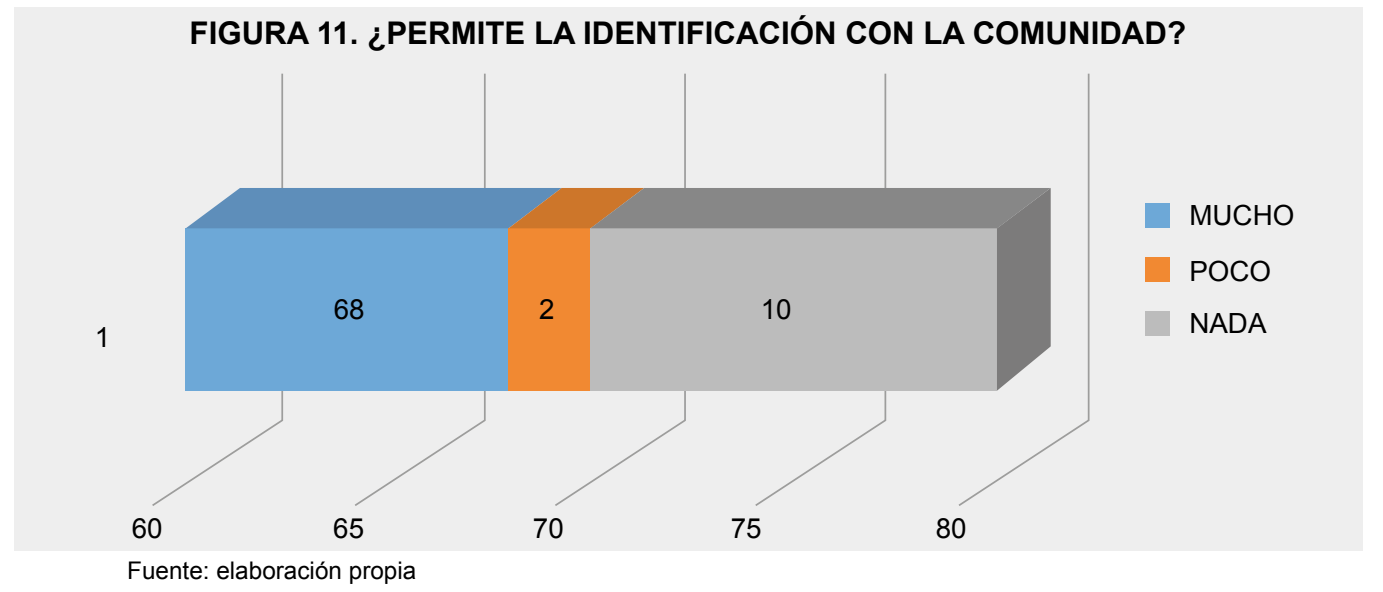


Tabla $N^{\circ} 11$ ¿ ¿La fiesta del agua permite la identificación de ustedes mismos con la comunidad?

\begin{tabular}{|c|c|c|c|c|c|c|c|c|c|c|}
\hline \multirow{2}{*}{ Ítems } & \multicolumn{2}{|c|}{$\begin{array}{c}\text { Mucho } \\
(\mathbf{2})\end{array}$} & \multicolumn{2}{c|}{$\begin{array}{c}\text { Poco } \\
(\mathbf{1})\end{array}$} & \multicolumn{2}{c|}{$\begin{array}{c}\text { Nada } \\
\text { (0) }\end{array}$} & \multicolumn{2}{c|}{ Anulado } & \multicolumn{3}{c|}{ Total } \\
\cline { 2 - 11 } & $\mathbf{N}^{\circ}$ & $\%$ & $\mathbf{N}^{\circ}$ & $\%$ & $\mathbf{N}^{\circ}$ & $\%$ & $\mathbf{N}^{\circ}$ & $\%$ & $\mathbf{N}^{\circ}$ & $\%$ \\
\hline 5 & 34 & 68 & 10 & 20 & 5 & 10 & 1 & 2 & 50 & 100 \\
\hline
\end{tabular}

\section{Análisis cualitativo}

El $68 \%$ (34) de los encuestados refiere que la fiesta del agua permite la identificación de ellos con la comunidad, un $20 \%$ (10) refiere que poco, mientras que el $10 \%$ (5) no cree. Un número significativo de los miembros de la comunidad está seguro de que esta fiesta permite la identificación de los pobladores con la comunidad.

FIGURA 12. ¿LA FIESTA DEL AGUA PERMITE LA UNIÓN DE LOS GRUPOS?

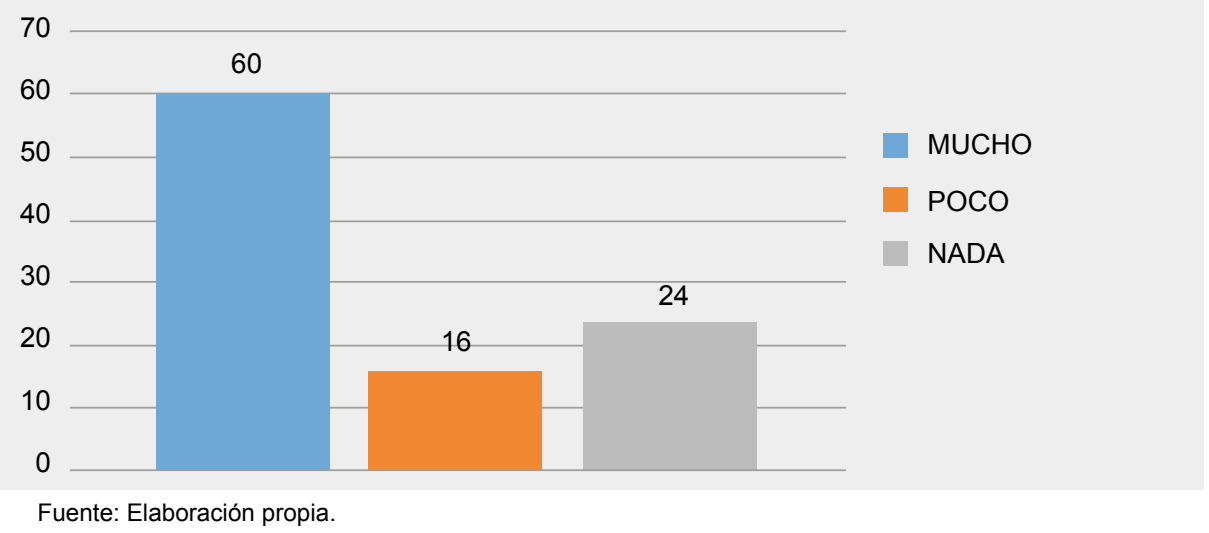

Tabla $N^{\circ}$ 12. ¿La fiesta del agua permite la unión de los grupos?

\begin{tabular}{|c|c|c|c|c|c|c|c|c|c|c|}
\hline \multirow{2}{*}{ Ítems } & \multicolumn{2}{|c|}{$\begin{array}{c}\text { Mucho } \\
(\mathbf{2})\end{array}$} & \multicolumn{2}{c|}{$\begin{array}{c}\text { Poco } \\
\text { (1) }\end{array}$} & \multicolumn{2}{c|}{$\begin{array}{c}\text { Nada } \\
\text { ( 0) }\end{array}$} & \multicolumn{2}{c|}{ Anulado } & \multicolumn{2}{c|}{ total } \\
\cline { 2 - 11 } & $\mathbf{N}^{\circ}$ & $\%$ & $\mathbf{N}^{\circ}$ & $\%$ & $\mathbf{N}^{\circ}$ & $\%$ & $\mathbf{N}^{\circ}$ & $\%$ & $\mathbf{N}^{\circ}$ & $\%$ \\
\hline 7 & 30 & 60 & 8 & 16 & 12 & 24 & - & - & 50 & 100 \\
\hline
\end{tabular}

\section{Análisis cualitativo}

El $60 \%$ (30) refiere que la fiesta del agua permite mucho la unión de los grupos, el 24\% (12) afirma que no permite la unión de los grupos, mientras que el $16 \%$ (8) opina que permite poco la unión de los grupos. En conclusión, los comuneros piensan que esta fiesta no permite la unión de los grupos. 


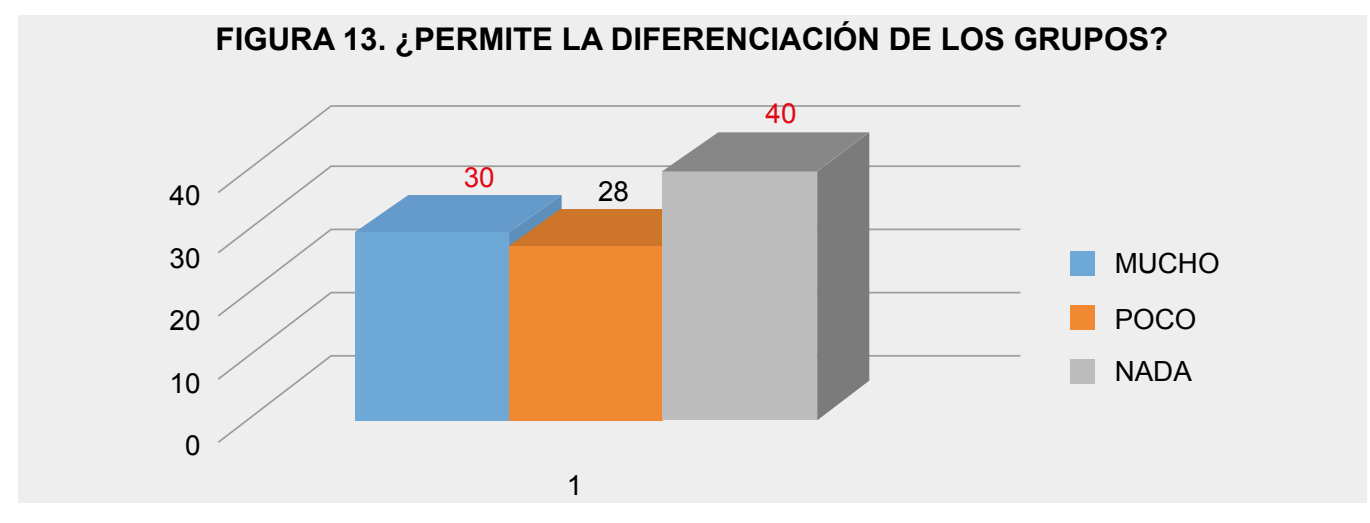

Fuente: elaboración propia

Tabla $N^{\circ} 13$. ¿La fiesta del agua permite la diferenciación de grupos?

\begin{tabular}{|c|c|c|c|c|c|c|c|c|c|c|}
\hline \multirow{2}{*}{ Ítems } & \multicolumn{2}{|c|}{$\begin{array}{c}\text { Mucho } \\
\text { (2) }\end{array}$} & \multicolumn{2}{c|}{$\begin{array}{c}\text { Poco } \\
\text { (1) }\end{array}$} & \multicolumn{2}{c|}{$\begin{array}{c}\text { Nada } \\
\text { (0) }\end{array}$} & \multicolumn{2}{c|}{ Anulado } & \multicolumn{2}{|c|}{ Total } \\
\cline { 2 - 11 } & $\mathbf{N}^{\circ}$ & $\%$ & $\mathbf{N}^{\circ}$ & $\%$ & $\mathbf{N}^{\circ}$ & $\%$ & $\mathbf{N}^{\circ}$ & $\%$ & $\mathbf{N}^{\circ}$ & $\%$ \\
\hline 6 & 15 & 30 & 14 & 28 & 20 & 40 & 1 & 2 & 50 & 100 \\
\hline
\end{tabular}

\section{- Validez cultural}

\section{Análisis cualitativo}

El $40 \%$ (20) de los sujetos encuestados opina que la fiesta del agua no permite la diferenciación de grupos, el 28 \% (14) afirma que permite poco la diferenciación de los grupos. Si pensamos que la fiesta de la comunidad es integración, encontramos que en el grupo de encuestados el $30 \%$ (15) opina que la fiesta del agua permite mucho la diferenciación de los grupos.

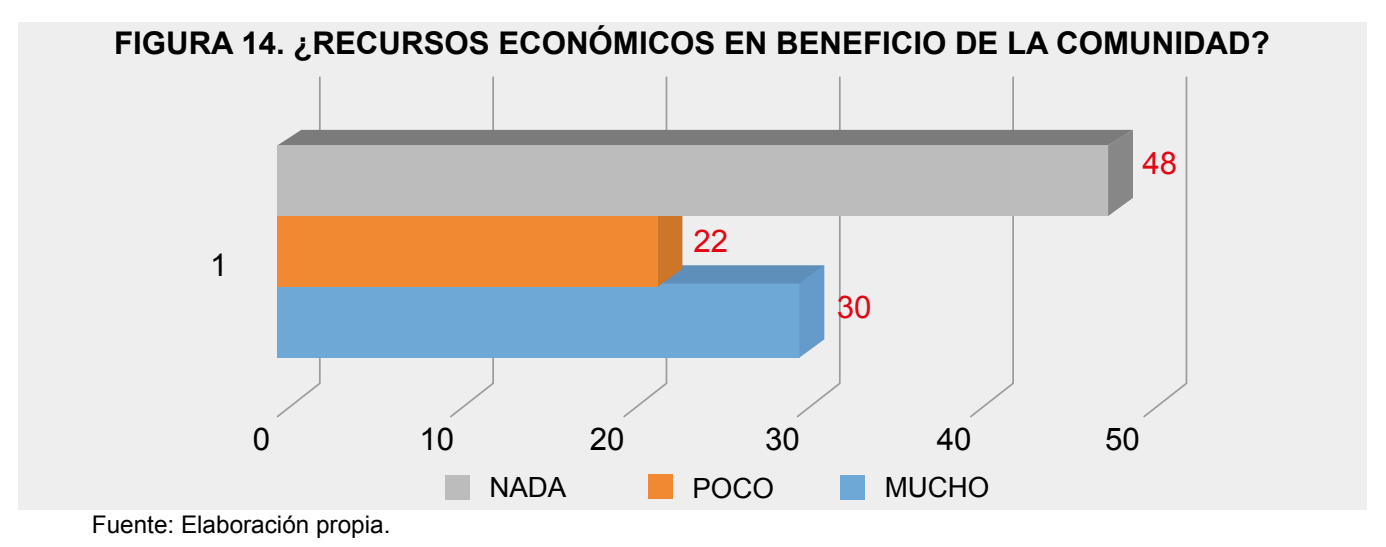


Tabla $N^{\circ} 14$. ¿La fiesta del agua genera recursos económicos en beneficio de la comunidad?

\begin{tabular}{|c|c|c|c|c|c|c|c|c|c|c|}
\hline \multirow{2}{*}{ Ítems } & \multicolumn{2}{|c|}{$\begin{array}{c}\text { Mucho } \\
\text { (2) }\end{array}$} & \multicolumn{2}{c|}{$\begin{array}{c}\text { Poco } \\
\text { (1) }\end{array}$} & \multicolumn{2}{c|}{$\begin{array}{c}\text { Nada } \\
\text { (0) }\end{array}$} & \multicolumn{2}{c|}{ Anulado } & \multicolumn{2}{c|}{ Total } \\
\cline { 2 - 12 } & $\mathbf{N}^{\circ}$ & $\%$ & $\mathbf{N}^{\circ}$ & $\%$ & $\mathbf{N}^{\circ}$ & $\%$ & $\mathbf{N}^{\circ}$ & $\%$ & $\mathbf{N}^{\circ}$ & $\%$ \\
\hline 8 & 15 & 30 & 11 & 22 & 24 & 48 & - & - & 50 & 100 \\
\hline
\end{tabular}

\section{Análisis cualitativo}

El $48 \%$ (24) de los sujetos encuestados afirma que la fiesta del agua no genera recursos económicos en beneficio de la comunidad, otro $22 \%$ (11) refiere que genera pocos recursos económicos en beneficio de la comunidad, mientras que el $30 \%$ (15) de sujetos afirma que genera mucho beneficio económico a la comunidad. Al parecer, la gente desconoce los beneficios económicos que aportan las fiestas costumbristas a la comunidad.

\section{FIGURA 15. ¿EXALTA SENTIMIENTOS ESPIRITUALES EN LA COMUNIDAD?}

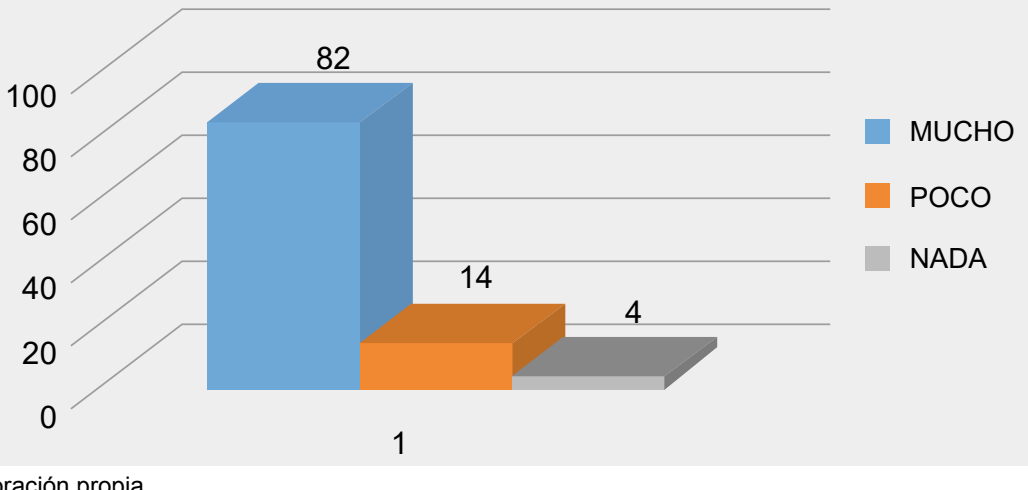

Fuente: Elaboración propia.

Tabla $N^{\circ} 15$. ¿La fiesta del agua permite exaltar sentimientos espirituales propios de la comunidad?

\begin{tabular}{|c|c|c|c|c|c|c|c|c|c|c|}
\hline \multirow{2}{*}{ Ítems } & \multicolumn{2}{|c|}{$\begin{array}{c}\text { Mucho } \\
(\mathbf{2})\end{array}$} & \multicolumn{2}{c|}{$\begin{array}{c}\text { Poco } \\
\text { (1) }\end{array}$} & \multicolumn{2}{c|}{$\begin{array}{c}\text { Nada } \\
\text { (0) }\end{array}$} & \multicolumn{2}{c|}{ Anulado } & \multicolumn{2}{c|}{ Total } \\
\cline { 2 - 11 } & $\mathbf{N}^{\circ}$ & $\%$ & $\mathbf{N}^{\circ}$ & $\%$ & $\mathbf{N}^{\circ}$ & $\%$ & $\mathbf{N}^{\circ}$ & $\%$ & $\mathbf{N}^{\circ}$ & $\%$ \\
\hline 9 & 41 & 82 & 7 & 14 & 2 & 4 & - & - & 50 & 100 \\
\hline
\end{tabular}

\section{Análisis cualitativo}

Un 82 \% (41) de las unidades de análisis afirma que la fiesta del agua permite exaltar sentimientos espirituales propios de la comunidad, un $14 \%$ (7) refiere que influye poco y solo un $4 \%$ (2) opina que no permite la exaltación de los sentimientos espirituales. En su mayoría las personas encuestadas afirman que la fiesta del agua permite la exaltación de sentimientos espirituales en la comunidad. 


\section{DISCUSIÓN DE LOS RESULTADOS}

El propósito de la presente investigación es describir el nivel de validez y los mecanismos procedimentales del acto de inscripción en el Registro de Marca de Servicios de la Fiesta Costumbrista del Agua (TUSUY) del distrito de Puquio, Ayacucho, 2016, por lo que presentamos la contrastación de los resultados obtenidos por los objetivos a la luz de los antecedentes y del marco teórico a partir de los hallazgos obtenidos. Así:

En el Objetivo específico $\mathrm{N}^{\circ}$ 1: Identificar el mecanismo procedimental para determinar la validez del acto de inscripción en el Registro de Marca de Servicios de la Fiesta Costumbrista del Agua (Tusuy), del distrito de Puquio, Ayacucho, 2016, en favor de una sociedad privada, se corrobora con los resultados obtenidos en la tabla 2 que el $70 \%$ (35) de los pobladores de la comunidad no conoce la Resolución de INDECOPI que registra la fiesta del agua, el $16 \%$ (8) conoce poco, el $14 \%$ (7) conoce mucho. Esto demuestra la indiferencia y la resignación de los sujetos miembros de la comunidad que desconocen los aspectos normativos de la Fiesta del Agua para reclamar sus derechos. Esto, además, coincide con la opinión de Herrera C., ${ }^{12}$ quien escribe que los mecanismos de inscripción en INDECOPI deben revisarse por muchas razones, y así mismo debe ser anulada la Resolución 012105 de INDECOPI porque ha sido obtenida de mala fe, y coincide también con De la Cruz, R., en su trabajo "Elementos para la protección sui generis de los conocimientos tradicionales colectivos e integrales desde la perspectiva indígena”, donde señala la necesidad de establecer mecanismos de protección de los conocimientos tradicionales de los pueblos indígenas sobre la base del derecho consuetudinario y las propias prácticas culturales, por constituir parte indisoluble de su cultura y representan un valor estratégico para el desarrollo socioeconómico de estos pueblos y una contribución al desarrollo sostenible de los países andinos. Todo este mecanismo se ampara en la Ley 28296. Ley General del Patrimonio Cultural de la Nación, que en su Artículo $2^{\circ}$. Propiedad de los bienes inmateriales sostiene que los bienes culturales inmateriales integrantes del Patrimonio Cultural de la Nación, por su naturaleza, pertenecen a la nación. Ninguna persona natural o jurídica puede arrogarse la propiedad de algún bien cultural inmaterial, siendo nula toda declaración en tal sentido, haya sido o no declarado como tal por la autoridad competente. Las comunidades que mantienen y conservan bienes culturales inmateriales pertenecientes al Patrimonio Cultural Inmaterial son los poseedores directos de dicho patrimonio. Asimismo, con la Resolución Directoral Nacional N³62/ INC-2005 "Declaran Patrimonio Cultural de la Nación a la Fiesta del Agua, Yaku Raymi”, se declara patrimonio por ser una fiesta que es costumbre autóctona quechua, que tiene su existencia desde la época precolombina, teniendo extraordinaria significación y simbolismos donde se rinde culto al agua, festividad andina por

12 Carlos Herrera, "Mi linda Andamarca", http//andamarca.blogspot.pe/2014/07/mamallay-mama-Registraron-la-fiesta-del-agua_27.html. 
excelencia, en concordancia con la Ley 28296. Ente emisor: Instituto Nacional de Cultura. Frente a todo esto, en la presente investigación se analiza y se concluye que las normas legales expuestas amparan dejar sin efecto la Resolución 012105-2013.

En el Objetivo específico $\mathrm{N}^{\circ}$ 2: Describir el nivel de validez del acto de inscripción en el Registro de Marca de servicios de la Fiesta Costumbrista del Agua (Tusuy), del distrito de Puquio, Ayacucho, 2016, a favor de una sociedad privada, la consulta hecha a la comunidad arroja los siguientes resultados:

En lo que se refiere a la validez legal, la tabla 6 muestra que el $76 \%$ (38) de los sujetos encuestados no sabe si las autoridades de Puquio pidieron la anulación del registro de la fiesta del agua, el $14 \%$ (7) sabe poco, y solo el 8 \% (4) sabe mucho. La comunidad desconoce sobre los asuntos legales de la fiesta de su comunidad. Sin embargo, en la presente investigación se puede demostrar que existen suficientes normas que justifican la validez legal de la fiesta del agua.

En cuanto a la validez social, se aprecia en la tabla 8 que el $56 \%$ (28) de los encuestados participa en la fiesta del agua de su comunidad, el $38 \%$ (19) participa poco y un $6 \%$ (3) no participa. Los datos indican que un número significativo de los miembros de la comunidad participa en la fiesta del agua. Coincidimos con Bendezú, R. ${ }^{13}$ en su libro Puquio y la Fiesta del Agua. En cuanto a la integración e identificación, Bendezú visualiza y propugna la integración e identificación de los hombres del Perú, sostiene que al integrarse la comunidad se inspira en los personajes del Tahuantinsuyo. Propugna que la integración es la identificación del vecino-misti con el indio campesino, en todas las formas de la vida espiritual y activa.

En lo que se refiere al nivel de validez cultural, la tabla 13 muestra que el $40 \%$ (20) de los sujetos encuestados refiere que la fiesta del Agua no permite la diferenciación de grupos, el $28 \%$ (14) afirma que permite poco la diferenciación de los grupos, y el 30 \% (15) opina que la fiesta del agua permite mucho la diferenciación de los grupos. En conclusión, esta fiesta une a los grupos, no diferencia ni discrimina. Coincidimos con Linares, M. cuando en un artículo en la Revista Caribeña de Ciencias Sociales planteó que "(...) la interacción cultural va estableciendo transformaciones históricas en las sociedades como proceso de comunicación constante"; no obstante, se resalta que en las comunidades tradicionales también se operan cambios, pero estos, cuando no alteran en lo esencial la identidad, mantienen el sistema de valores, normas y creencias que a pesar de haber evolucionado sustentan su identidad.

13 R. A. Bendezú N., Puquio y la Fiesta del Agua, tercera edición (Ica, 2010). 


\section{CONCLUSIONES}

La Fiesta Costumbrista del Agua (Tusuy) es una tradición cultural nativa del distrito de Puquio y los distritos aledaños. Con la Ley 28296 (Ley General del Patrimonio Cultural de la Nación) y la RDN N³62/INC-2005, se la declara Patrimonio Cultural de la Nación. Su existencia data desde la época precolombina, con extraordinaria significación y simbolismos en el culto al agua.

Las normas legales expuestas amparan dejar sin efecto la Resolución 012105-2013, porque la Fiesta Costumbrista del Agua (Tusuy) del distrito de Puquio, Ayacucho, 2016, debe ser a favor de la comunidad y no de una sociedad privada.

El nivel de validez social de la Fiesta del Agua fortalece la integración de los miembros de la comunidad, lo que permite mantener la identidad indígena de las comunidades nativas de Puquio.

La Fiesta costumbrista del Agua (Tusuy) del distrito de Puquio, Ayacucho, 2016, permite la interacción cultural estableciendo transformaciones históricas en las sociedades como proceso de comunicación constante.

\section{RECOMENDACIONES}

1. Las comunidades nativas deben ser capacitadas en el conocimiento de los bienes culturales inmateriales integrantes del Patrimonio Cultural de la Nación, que por su naturaleza pertenecen a la Nación, y ninguna persona natural o jurídica puede arrogarse la propiedad de algún bien cultural inmaterial.

2. Las autoridades edilicias, políticas, judiciales, comunales, organizaciones de base y pueblo en general del distrito de Puquio deben solicitar de inmediato la nulidad del Registro de la Propiedad Industrial, la denominación Puquio Sequia Tusuy Fiesta del Agua y logotipo, según Resolución No 012105.2013/DSD-INDECOPI; por vía administrativa, fundamentando el pedido con las pruebas del caso y la tasa correspondiente. Si la solicitud de nulidad vía administrativa no prosperase, se sugiere iniciar las acciones legales vía judicial a la institución responsable del registro.

3. Las comunidades nativas deben exigir el respeto y valoración de sus costumbres tradicionales dentro del marco del patrimonio cultural inmaterial, como expresión de la cultura viva.

4. Las autoridades de cultura deben promover el diálogo entre culturas y fomentar el respeto hacia otros modos de vida. 


\section{REFERENCIAS}

- Bendezú N., Róger. A. Puquio y la Fiesta del Agua. Tercera edición. Ica, 2010.

- De la Cruz, R., G. Muyuy, A. Viteri, G. Flores, J. González, J. Mirabal y R. Guimaraez. Elementos para la protección sui generis de los conocimientos tradicionales colectivos e integrados desde la perspectiva indígena. Caracas: Corporación Andina de Fomento y Secretaría de la Comunidad Andina, 2005.

- Chiroque, Ch. Fiesta del Agua. Educación Esperanza, Blog, 23 de diciembre de 2011.

- Decreto Ley No 22175: Ley de Comunidades Nativas y de Desarrollo Agrario de las Regiones de Selva y Ceja de Selva del 9 de mayo de 1978

- Fernández, Carlos. Naturaleza tridimensional de la persona jurídica. Con especial referencia al derecho peruano. DIKÉ: Portal de Información y Opinión legal, Pontificia Universidad Católica del Perú. http://dike.pucp.edu.pe/bibliotecadeautor_carlos_fernandez_cesareo/ articulos/ba_fs_.

- Gómez, M. y M. del Villar. "El concepto de propiedad y los conocimientos tradicionales indígenas”. En-clav. pen 3, № 5, México (jun. 2009) 115-135.

- Hernández S., Roberto, Carlos Fernández C. y Pilar Baptista L. Metodología de la investigación. Sexta edición. México: Mc Graw Hill Interamericana, 2006.

- Herrera, Carlos. "Mi linda Andamarca”. http//andamarca.blogspot.pe/2014/07/mamallay-mama-Registraron-la-fiesta-del-agua_27.html.

- Ley No 24656: Ley General de Comunidades Campesinas del 14 de abril de 1987.

- Peña J., A. "La propiedad originaria en América: el derecho de propiedad en las comunidades andinas y amazónicas del Perú”. Ius et Veritas, Nº 45 (2012): 245-272.

- Tincopa, J. "Pukiu llaqtapi Yaku Raymi o Fiesta del Agua en Puquio”. Qawaq, No 13 (1 de enero - 1 de abril de 2011): 15-20. http://revistaqawaq.blogspot.pe/2010/12/angusay-yaku-raymi-enpuquio.html.

- UNESCO. ¿Qué es el patrimonio cultural inmaterial? http://www.unesco.org/culture/ich/ es/ que-es-el- patrimonio-inmaterial-00003 


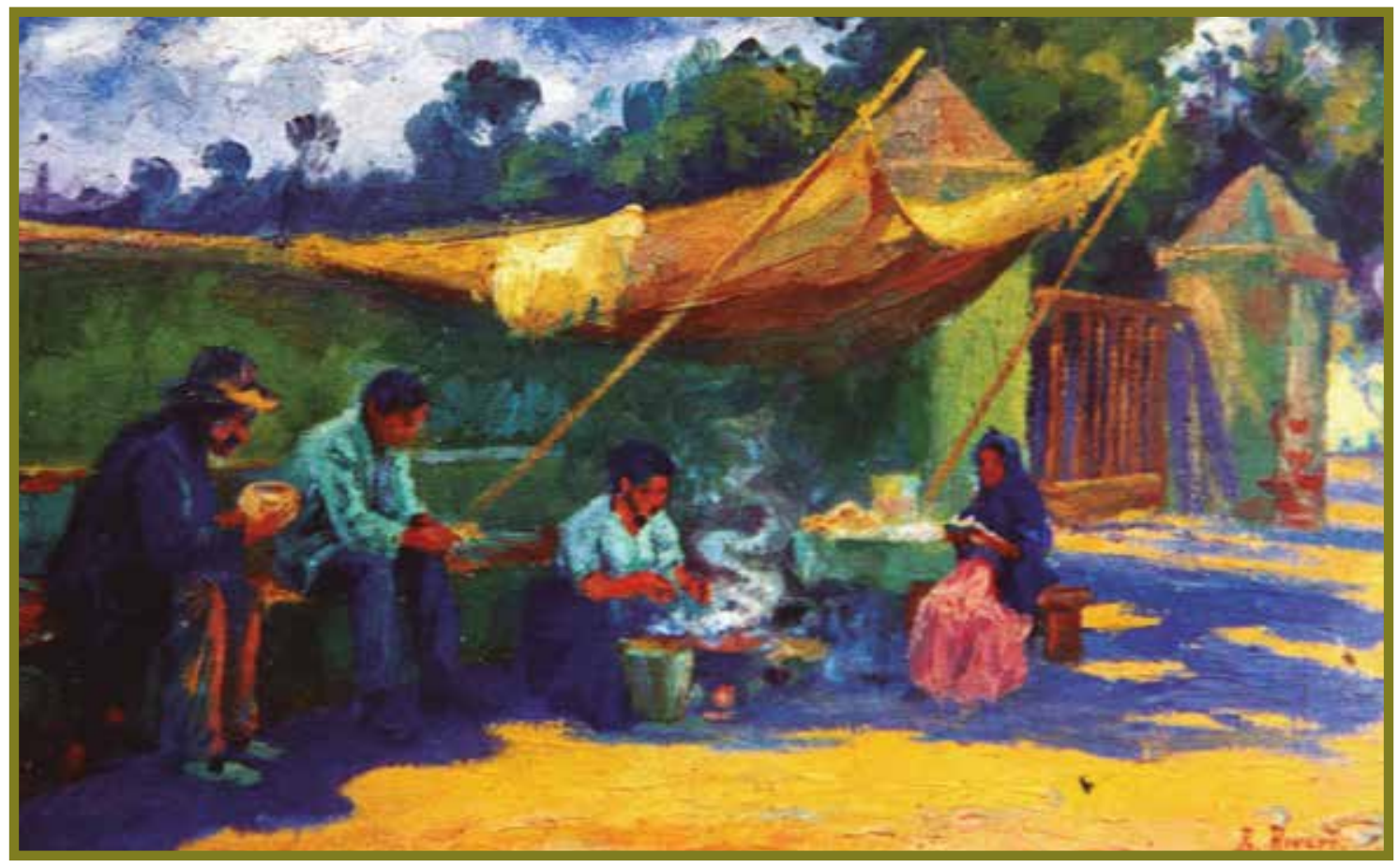

Mercadillo. Óscar Allaín 